\section{Impacto de la pandemia de gripa de 1918-1919 sobre el perfil de mortalidad general en Boyacá, Colombia}

\section{Impact of the flu pandemic of 1918-1919 on the general mortality profile in Boyacá, Colombia.}

Juan Manuel Ospina Díaz

Profesor asociado de la Escuela de Medicina / Universidad Pedagógica y Tecnológica de Colombia. Museo de Historia de la Medicina y la Salud UPTC. Antiguo Hospital San Rafael

Tunja - Boyacá - Colombia.

duendex56@yahoo.com

\section{Abel Fernando Martínez Martín}

Profesor asociado de la Escuela de Medicina / Universidad Pedagógica y Tecnológica de Colombia. Museo de Historia de la Medicina y la Salud UPTC. Antiguo Hospital San Rafael Tunja - Boyacá - Colombia. abelfmartinez@gmail.com

\section{Oscar Fernando Herrán Falla}

Profesor titular de la Facultad de Salud Universidad Industrial de Santander

Centro de Investigaciones Epidemiológicas. Facultad de Salud Universidad Industrial de Santander Bucaramanga - Colombia. herran28@msn.net.com

Recebido para publicação em julho de 2007. Aprovado para publicação em maio de 2008.
OSPINA DÍAZ, Juan Manuel; MARTÍNEZ MARTÍN, Abel Fernando; HERRÁN FALLA, Oscar Fernando. Impacto de la pandemia de gripa de 1918-1919 sobre el perfil de mortalidad general en Boyacá, Colombia. História, Ciências, Saúde - Manguinhos, Rio de Janeiro, v.16, n.1, jan.-mar. 2009, p.53-81.

\section{Resumen}

Objetivo: Describir el impacto epidemiológico y social de la pandemia de gripa de 1918-1919 en 41 municipios de Boyacá, Colombia. Metodología: Estudio descriptivo empírico-analítico, histórico, con enfoque epidemiológico. Se estableció el volumen y estructura de la población y se determinaron tasas de mortalidad para las variables de tiempo, persona y lugar. Resultados: La pandemia se inició en octubre de 1918 en Bogotá y se extendió a Boyacá por carretera. No se encontraron las tres oleadas cronológicas descritas en la literatura. Encontramos diferencias significativas en el comportamiento de la pandemia de gripa en el departamento de Boyacá en comparación con lo descrito en Europa y Norteamérica por la literatura especializada.

Palabras clave: pandemia gripa (19181919); mortalidad; Boyacá; Colombia.

Abstract

Objective: To describe the epidemiological and social impact of the flu pandemic of 1918-1919 in 41 municipalities of Boyacá, Colombia. Methodology: descriptive, analytical-empiric, historic study with an epidemiological focus. The volume and structure of the population is established and determines the mortality rates for the variables of time, person and place. Results: The pandemic began in October 1918 in Bogotá and reached Boyacá by road. The three chronological waves found in the literature were not identified. We found a significant difference in the behavior of the flu pandemic in the department of Boyacá with that described in Europe and North America by the specialized literature.

Keywords: flu pandemic (1918-1919); mortality; Boyacá; Colombia. 
$\mathrm{D}$ urante el siglo XX, ocurrieron pandemias de gripa en 1918, 1957 y 1968. Se estima que la pandemia de 1918 provocó la muerte de cerca de cuarenta millones de personas en menos de un año. Las pandemias de 1957 y 1968 fueron menos graves: entre un millón y cuatro millones de defunciones calculadas, principalmente en grupos de riesgo tradicionalmente alto como los ancianos (Ayora-Talavera, 1999, p.58). Diversos autores coinciden en afirmar que el grupo de edad más afectado en 1918 fue el de hombres y mujeres, entre veinte y cuarenta años (Crosby, 2003, p.202-226).

A partir de la experiencia de las epidemias y del conocimiento del virus, se han estudiado patrones de comportamiento y de difusión de la gripa de 1918-1919, ajustados a las pandemias históricas. En las últimas décadas, la pandemia de gripa de 1918 ha suscitado un creciente interés en Europa y Estados Unidos. Cabe señalar, entre otros, el estudio de Barry (2004) y los volúmenes colectivos editados por Van Hartesveldt (1992) y por Phillips y Killingray (2003) sobre la situación mundial, los de Echeverri Dávila (1993), Porras Gallo (1994), Martínez Pons (1999) y el volumen colectivo editado por Bernabeu Mestre (1991) sobre España; así como los de Crosby (2003) y Byerly (2005) sobre Estados Unidos. A pesar de la abundante literatura referida, llama la atención la falta de estudios sobre Asia, África, Europa Oriental y Latinoamérica, con la excepción de Brasil (Abrão, 1998; Bertolli Filho, 2003; Martínez Martín, Manrique Abril, Meléndez Alvarez, 2007).

En Colombia, Durán Sánchez (2006), Zambrano (dic. 1987), García Medina (dic. 1918), Laverde (1918), Echeverri Dávila (1993), Phillips y Killingray (2003), Noguera (2004) y la Junta de Socorros de Bogotá (1918) registran las primeras muertes en Bogotá a comienzos de octubre de 1918, siendo este hecho muy documentado. La prensa escrita de la época, de ciudades como Medellín y Manizales (El Espectador, 1918); Tunja (La Linterna y El Deber, 1918); Barranquilla (La República, 1918); Túquerres y Quito (El Progreso, 1918); Bucaramanga (La Palabra Católica, 1918) y Cartagena (García Usta, 2000, p.115) registra la aparición de la pandemia en fechas posteriores a las de la capital de la República, afectando en mayor proporción y con más severidad a las zonas andinas ubicadas a mayor altura sobre el nivel del mar. La abundancia de fuentes primarias contrasta con la escasez de investigaciones sobre la pandemia en Colombia. La mayoría de los trabajos registran datos de Bogotá, a la que sitúan como el epicentro de la pandemia en el país.

La aparición de una próxima pandemia de gripa es solo cuestión de tiempo. No se puede predecir la gravedad, pero programas de modelación indican que su impacto en Estados Unidos podría ser considerable. En ausencia de medidas de control (vacunas o medicamentos), entre el 15\% y el 35\% de la población estadounidense podría verse afectada por una pandemia de gripa y el impacto económico podría oscilar entre 71.300 y 166.500 millones de dólares (USA, 2006).

La gripa es producida por un virus Orthomyxoviridae, género Influenzavirus. La envoltura presenta dos glicoproteínas: la hemaglutinina y la neuroaminidasa. Existen tres tipos de virus, A, B y C. Importantes son los tipos A y B, ya que el C no produce epidemias (Bennett, Plum, 1996, p.2023). El virus causante de la pandemia de 1918 fue del subtipo H1N1. El aislamiento del primer virus de la gripa, en 1933, por Smith, Andrews y Laidlaw (AyoraTalavera, 1999, p.57-61) dio lugar a la aparición y crecimiento posterior de una nueva literatura sobre la gripa de carácter epidemiológico. 
Investigaciones adelantadas en EUA y Europa permiten aproximaciones a las condiciones en las que se desarrolló la enfermedad. En Colombia, los únicos estudios publicados sobre la pandemia de gripa se limitan a describir lo acontecido en Bogotá. Departamentos como Boyacá, uno de los más poblados de la época y, según datos preliminares, de los más afectados, no cuentan con ninguna investigación que permita conocer el impacto regional de la pandemia. De hecho, esta investigación es la primera que se adelanta en Colombia, intentando abarcar una muestra representativa de los 103 municipios existentes en Boyacá, en la época que se describe.

\section{Objetivo general}

Describir el impacto epidemiológico y social de la pandemia de gripa de 1918-1919 en una muestra de 41 municipios del departamento de Boyacá, Colombia, para identificar factores de riesgo y protectores que puedan contribuir al control preventivo de futuras pandemias.

\section{Materiales y métodos}

Se incluyeron 41 municipios (Figura 1). A partir de los censos de población de 1912, 1918 y 1928, se diseñó una proyección poblacional por género y grupo de edad. Se recogió de los libros de defunción de los archivos parroquiales, la información referida a la fecha de la defunción, el sexo y la edad del fallecido, causa del fallecimiento, municipio, área de residencia (urbana o rural). En total se obtuvieron, durante los cuatro años estudiados, 17.421 registros de defunción. Adicionalmente, se obtuvo información sobre la altura promedio del municipio sobre el nivel del mar y estructura vial existente en el período estudiado. Se realizó búsqueda bibliográfica para obtener información relevante sobre el contexto socioeconómico y cultural de la época, tanto en el nivel nacional como regional. Con la información obtenida se ensambló en el paquete estadístico Epi Info ${ }^{\circledR}$ una base de datos que incluyó las variables día, mes y año de la defunción, edad del fallecido en años o fracción de año, municipio, altura sobre el nivel del mar, código de la causa de la defunción, sitio de la defunción urbano o rural y el primer apellido del fallecido.

Las causas de defunción se organizaron y codificaron de la siguiente manera:

1.Gripa

2.Enfermedades respiratorias agudas

3. Enfermedades gastrointestinales agudas

4.Enfermedades cardiovasculares

5. Tumores

6.Síndrome de afectación general

7.Enfermedades respiratorias crónicas

8. Trauma o lesión de causa externa

9.Enfermedades neurológicas

10. Enfermedades renales

11.Enfermedades gastrointestinales crónicas 
12. Enfermedad perinatal (incluye mortalidad materna y del neonato)

13. Otras mal definidas

Para efectos del análisis de mortalidad por gripa, solo se incluyeron los registros de defunción en los que este diagnóstico se consignaba como causa directa de la muerte.

Teniendo la posibilidad de aproximar el volumen y estructura poblacional, la tasa cruda de mortalidad se estratificó en tasas específicas por grupos de edad, con lo que se obtuvieron medidas ajustadas más concluyentes que el simple número absoluto de defunciones para cada municipio y para la totalidad de la muestra. Eso permitió establecer comportamiento promedio mensual y un perfil de mortalidad característico de antes, durante y después de la pandemia.

El análisis específico de la pandemia se centró en el período de octubre de 1918 a enero de 1919. Para ello se determinaron las tasas totales y específicas de mortalidad y se aproximó, mediante la estimación del riesgo atribuible a la exposición, el impacto de la pandemia en el nivel local y regional.

Igualmente fue posible identificar en un análisis exploratorio, bivariado, algunos factores de riesgo asociados a la probabilidad de morir si se contraía la gripa, los cuales se incluyeron en un modelo explicatorio de regresión lineal.

Figura 1: Municipios de Boyacá (Colombia) incluidos en el estudio

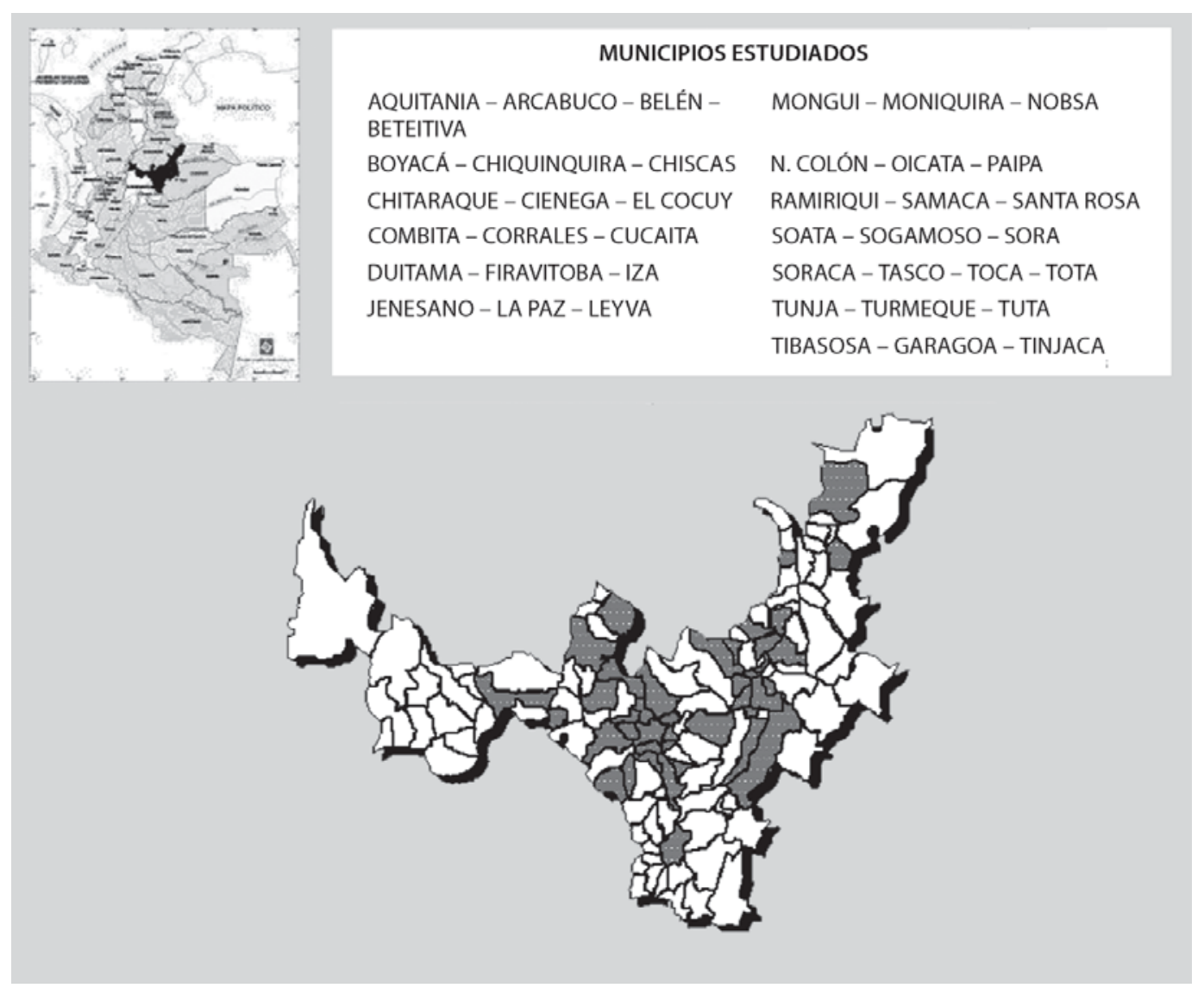




\section{Resultados}

\section{Contexto socioeconómico y cultural de Colombia y Boyacá en 1918-1919}

El departamento de Boyacá se localiza en el centro de Colombia, atravesado por la rama oriental de la cordillera de los Andes; para la época contaba con una extensión de $8.630 \mathrm{~km}^{2}$ de los cuales más de la mitad eran terrenos baldíos. En el centro del departamento se localiza, sobre el eje de la cadena montañosa, el altiplano, de manera que partiendo del centro, hacia el oriente y el occidente se vierten afluentes fluviales que conforman las hoyas hidrográficas de los ríos Magdalena al occidente, y Meta, Upía y Casanare al oriente.

Los pisos térmicos son un sistema de medida que nos permite definir la temperatura de una zona, de acuerdo a la altura sobre el nivel del mar en que se encuentre. Este sistema solo se puede aplicar en el trópico americano, debido a sus características geográficas y atmosféricas. Dentro de los pisos térmicos, se han definido cinco niveles denominados cálido, templado, frío, páramo y glacial.

El piso cálido comprende las zonas localizadas entre 0 y 1.000 m.s.n.m.; estas áreas presentan una temperatura promedio superior a los 24 grados centígrados. El piso templado comprende las áreas ubicadas entre los 1.000 y 2.000m.s.n.m., con temperaturas que oscilan entre los 17 y $24^{\circ} \mathrm{C}$., ubicándose en las zonas bajas de las montañas. El frío corresponde a las zonas localizadas entre los 2.000 y 3.000m.s.n.m., presenta temperaturas que oscilan entre los 12 y $17^{\circ} \mathrm{C}$, ubicándose en las partes altas de las montañas. El páramo se presenta en las áreas situadas entre los 3.000 y 4.000m.s.n.m., con temperaturas que oscilan entre los 6 y $12^{\circ} \mathrm{C}$. Se localiza en la parte superior de las montañas. El glacial corresponde a las zonas con alturas superiores a los 4.000 metros sobre el nivel del mar, con temperaturas inferiores a los $6^{\circ} \mathrm{C}$ (Ideam, 4 jun. 2001). En toda la geografía andina se registran dos temporadas lluviosas: la primera, de abril a mayo y la segunda, de octubre a noviembre.

Mientras las potencias mundiales disputaban la Primera Guerra Mundial, confrontación por la hegemonía y el control de colonias y mercados mundiales, en Colombia, la guerra ocasiona la suspensión de flujos comerciales y financieros y paralización de obras públicas, causando desempleo. El gobierno acusa déficit en sus rentas, acude entonces a préstamos de bancos y ciudadanos ricos (Londoño Vega, Londoño Vélez, 1989, p.324). Esto ocurría en momentos en que intentaba apenas resarcirse del fracaso de la política económica radical de mediados del siglo XIX, experimento que se hundiría definitivamente con el conflicto de la llamada Guerra de los Mil Días que consolidaría un régimen político de corte conservador: la hegemonía conservadora.

Como fórmula política, la hegemonía integró principios del liberalismo económico, intervencionismo borbónico, antimodernismo del corte del papa Pío IX y un nacionalismo cultural hispanófilo (Palacios, 1999, p.47). Al despuntar el siglo XX, la sociedad colombiana, eminentemente rural, era monopolizada por hacendados en el plano económico y social. Estaba controlada políticamente por el Partido Conservador e ideológica y culturalmente, por el clero católico. La mayor parte de los habitantes de Colombia residía en área rural (Vega Cantor, 2000, p.54).

El territorio colombiano de $1.148 .748 \mathrm{~km}^{2}$ estaba prácticamente deshabitado, ya que el $75 \%$ eran tierras baldías. La orografía de tres cadenas montañosas establecía la casi total 
incomunicación de las cinco regiones geográficas que solo se podía solventar mediante recuas de mulas, transporte fluvial y unos escasos $1.500 \mathrm{~km}$ de tendido ferroviario, de los cuales ninguno cruzaba Boyacá. Colombia era un país desintegrado en lo interno y aislado en el contexto externo (Arcila, 1991, p.45).

La demanda mundial de materias primas ahondó la brecha entre las tierras frías de viejo asentamiento desde tiempos coloniales que producían para el mercado interno, como el altiplano cundiboyacense, y las tierras cálidas y templadas, colonizadas recientemente para incorporarlas a la producción de exportables, de los cuales solo el café se consolidó después de la década de 1920. Emergen en el sector productivo del agro, el comerciante hacendado de café en las vertientes de las cordilleras central y oriental, el engordador de ganado en la costa y el plantador de caña de azúcar en la costa y el valle del Cauca (Palacios, 1999, p.26).

En el plano del control social, el acercamiento del Estado con la iglesia consolidó a las jerarquías católicas como institución reguladora de un orden (Cortés, 1998, p.109). La influencia de la iglesia católica y del clero colombiano fue muy fuerte y alcanzó varios aspectos de la vida nacional: la educación, la salud, la política, la problemática social. El clero, ayudado por las clases altas, se preocupó por fundar instituciones de beneficencia, dedicadas al cuidado de indigentes, huérfanos, dementes, delincuentes, realizar obras de caridad y fundar sociedades de artesanos y de obreros (Llano Restrepo, Campuzano Cifuentes, 1994, p.67).

En la medicina, la ideología médica registra la evolución del modelo anatomopatológico hacia los modelos fisiopatológico y etiopatológico: la medicina de laboratorio (Miranda Canal, 1989, p.263-264).

Desde 1873, se inicia en Colombia la institucionalización de la higiene pública francesa, un incipiente movimiento higienista que genera el tránsito de la higiene hacia la medicina tropical y posteriormente a la salud pública. Llegan a Colombia la teoría microbiana y la bacteriología, dando lugar a la 'bacteriologización' de la higiene pública (Quevedo Vélez, 2004, p.55).

Las pésimas condiciones de salud y asistencia social, la pobreza y una desastrosa situación higiénica eran la nota dominante en la Colombia de las primeras décadas del siglo XX, circunstancias que se agravaban por la inexistencia o baja cobertura de los servicios públicos. En 1910, la esperanza de vida del colombiano era de 30 años, la tasa de mortalidad infantil ascendía a 250 por mil y la tasa de mortalidad bruta era de 35 por mil (Vega Cantor, 2000, p.54).

Estos fenómenos de transición y transformación socioeconómica relegaron a Boyacá y afianzaron su aislamiento y atraso. Hasta el censo de 1870, el estado soberano de Boyacá aparece como el más poblado de Colombia con 499.000 habitantes, aproximadamente, el $18,5 \%$ de los 2,6 millones del país. En 1887, con 61.5000 y en 1898 con 685.000, el departamento de Boyacá pasa a ser el segundo más poblado después del Cauca.

Comenzado el siglo XX, registra este departamento poblaciones de 503.000 habitantes en 1905 y 586.000, según el censo de 1912 (Martínez Martín, 2006, p.41) que lo relega al tercer lugar. Es probable que este fenómeno regresivo en el volumen poblacional se explique, de una parte, por el impacto de las guerras de finales del siglo XIX (Ortiz Mesa, 2004, p.83) y por la emigración permanente de campesinos boyacenses hacia áreas de colonización cafetera y de 
explotación ganadera, por el otro lado. En consecuencia, muchos emigrantes partieron a abrir monte en zonas de frontera de clima templado y cálido (Palacios, 1999, p.28).

En la segunda mitad del siglo XIX y comienzos del XX, el poder de compra de los jornales en el altiplano cundiboyacense cayó a la mitad frente a cuatro productos básicos de la dieta (maíz, carne, harina de trigo y papa). Como factores de expulsión, se impusieron además la presión demográfica y el acaparamiento de los suelos planos y fértiles por familias de terratenientes y comerciantes.

La decadencia poblacional de Boyacá se relaciona también con la pérdida de prestigio en el conjunto nacional en relación con el reconocimiento que tuvo durante el período colonial, sobre todo en lo económico, incluyendo una escasísima inserción en la economía nacional prácticamente inexistente a escala mundial; lo mismo puede decirse de la modernización cultural, poco difundida en una sociedad campesina tradicional (Guerrero, 1991, p.46). "El pueblo boyacense permanece dentro de sus serranías y sus planicies como extraño al movimiento de civilización que hoy conmueve al país... . La higiene es completamente desconocida" (Peñuela Rodríguez, 1923, p.88).

En la meseta cundiboyacense, la producción agrícola se sustentaba principalmente en alimentos de consumo directo que contaban con mercados estrictamente locales o cultivos de subsistencia; en gran escala, solo trigo y cebada se había establecido en manos de los terratenientes (Machado, 1986, p.13). Según el censo de 1912, eran propietarios urbanos el $20 \%$ de los habitantes, mientras que la propiedad rural se concentraba en menos del 5\% de la población. Más del 80\% de los varones era analfabetos, el 39,6\% de los hombres trabajaba de manera independiente y el 18,8\% se declaraba asalariado. Alrededor del 12\% de los niños en edad escolar asistía a la escuela. Es importante anotar que en este censo no se tiene en cuenta a las mujeres, ya que solo cuantifica a los hombres (Colombia, Censo 1912).

Sobre las condiciones socioeconómicas de la capital del departamento de Boyacá, a finales de septiembre de 1918, aparece en El Deber (27 sept. 1918), una noticia de la Junta del Asilo de San José, titulada "Los mendigos sin pan ni abrigo" que trata sobre los pordioseros que abundan en la ciudad: "andan por las calles de Tunja muchos mendigos, porque la Junta del Asilo de San José no ha podido sostenerlos a todos ... . Sabedores los pordioseros de los pueblos vecinos que ahora no se les encierra en el Asilo de San José, se vienen sobre Tunja a formar el triste cortejo de otros tiempos y los vemos golpear en los portones y asediar los zaguanes".

Desde finales del siglo XIX y primeras décadas del siglo XX, existen hospitales en Tunja, Paipa, Moniquirá, Chiquinquirá, Santa Rosa de Viterbo, El Cocuy, Guateque, Garagoa, Villa de Leiva y Soatá (El Boyacense, 7 abr. 1888, p.875), todos regentados por juntas y asociaciones locales de beneficencia con amplia participación del clero. La administración estaba a cargo de un síndico - mayordomo y la atención directa, agenciada por religiosas y mujeres mayores contratadas para este fin (Martínez Martín, Alvarado, Carvajal, 2002, p.131). El hospital de Tunja era atendido por las Hermanas Dominicas de la Presentación. El edificio se hallaba casi en ruinas y carecía por completo de higiene; los pisos de adobe y ladrillo estaban deteriorados; contaba solamente con un pequeño botiquín de urgencia. A los enfermos no se les podía suministrar sino purgantes, remedios caseros y drogas muy rudimentarias; no había servicio de cirugía por falta de sala adecuada e instrumental. Sólo 
existían treinta catres de madera en mal estado, las camas se componían de esteras de junco y de hojas de maíz; los enfermos tenían que acostarse con la misma ropa con que llegaban porque el hospital no les podía ofrecer ropa de cama. El gobierno solo reconocía 12 centavos diarios por cada enfermo, dinero que pagaba con gran retardo y trabajo. El hospital estaba atendido por dos Hermanas de la Caridad que no recibían remuneración y tomaban gratuitamente la alimentación en el vecino Colegio de la Presentación. Los enfermos recibían caritativamente los alimentos sobrantes del personal del citado colegio. No había médico oficial; el doctor Gil Márquez acudía gratuitamente a visitar a los enfermos, aliviándolos en lo posible y su generosidad llegaba hasta obsequiar, de su propia botica y consultorio, los elementos para curaciones de urgencia (Rojas, 1994, p.238).

\section{Aspectos demográficos}

Como la pandemia de gripa ocurrió en 1918, para efectos de la estimación poblacional y la distribución por grupos de edad, fueron tenidas en cuenta las frecuencias relativas al censo de este mismo año, adelantado durante el gobierno de Marco Fidel Suárez para el 14 de octubre y aprobado por el Congreso Nacional según ley $8^{\text {a }}$ del 19 de septiembre de 1921. Para efectos de estimación de la dinámica poblacional, se encontró que la tasa de crecimiento poblacional para el conjunto de los 41 municipios analizados fue de 1,7\% para el período comprendido entre 1912 y 1918 y de 3,8\% para el lapso 1918 a 1928.

En 1918, con un total de 586.599 habitantes, la estructura poblacional, representada como pirámide, refleja una forma de tipo expansivo con una gran concentración de población en edades jóvenes, característica de los países en vía de desarrollo (Gráfica 1). En cuanto a la distribución espacial de la población, se encontró que más del 70\% se localizaba en áreas rurales.

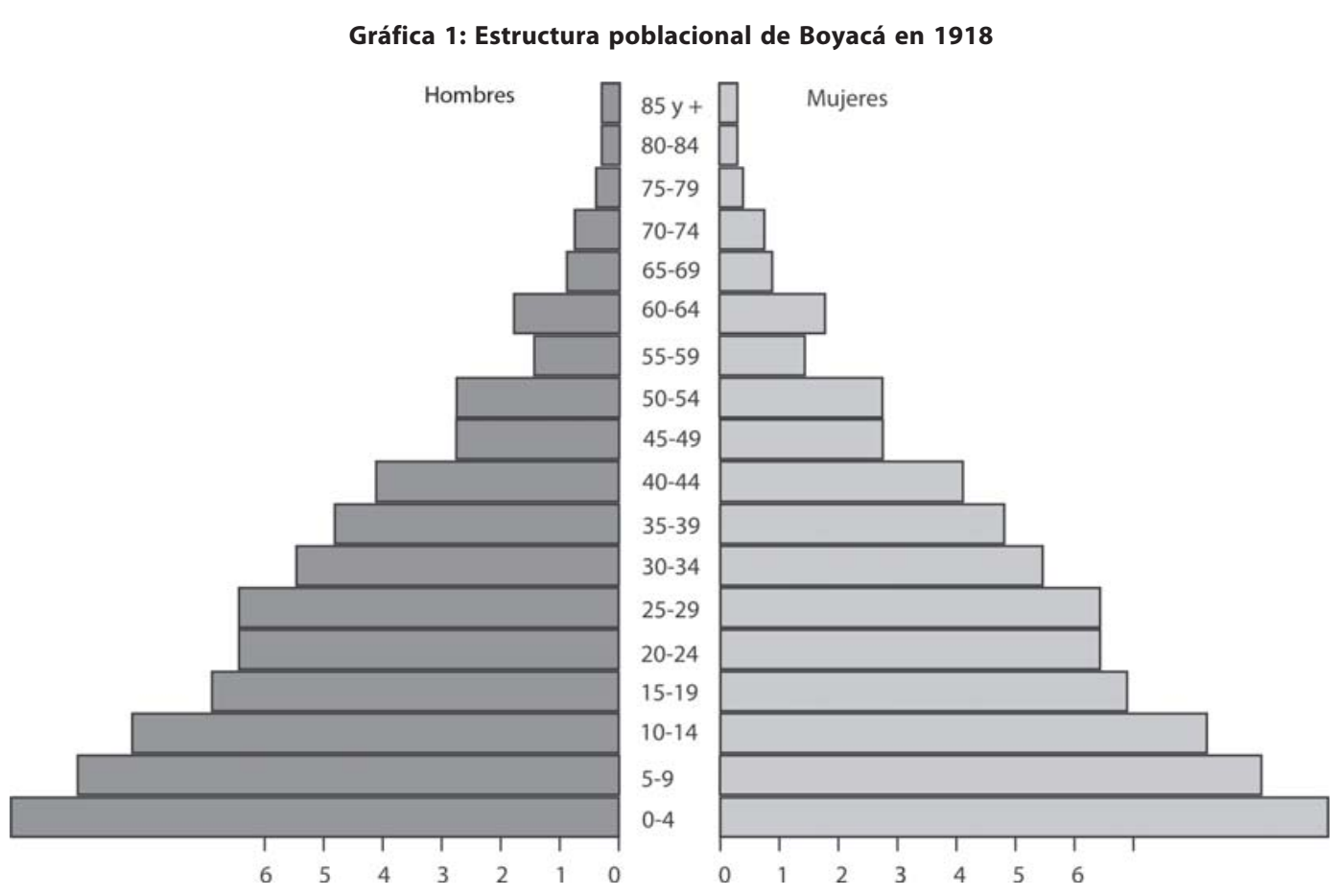




\section{Mortalidad por gripa antes de la pandemia}

Los registros parroquiales de defunción durante el período 1912-1917, antes de la pandemia de gripa de 1918, dan cuenta de un total de 144 fallecimientos con ese diagnóstico, de los cuales 88 (el 61\%) ocurre entre 1916 y 1917 lo que sugiere un aumento gradual de la frecuencia de esta patología, atribuible a la crítica situación socioeconómica, malnutrición y hábitat de piso térmico frío, más evidente en tres provincias. Se aprecia además, un comportamiento temporal de la frecuencia de mortalidad, con carácter estacional, relacionado con la temporada de transición a las lluvias que ocurren de manera cíclica de febrero a abril y de agosto a octubre. El análisis global de la mortalidad en estos seis años muestra que, por grupos de edad, los menores de cinco años y los mayores de sesenta aportan las mayores tasas de mortalidad por gripa, mientras que por género se encuentra el mismo número de fallecidos para cada sexo.

\section{La mortalidad general antes de la pandemia: 1917}

La mortalidad por gripa durante el año previo a la pandemia representa apenas algo más del 1\%. En conjunto, el perfil de mortalidad se corresponde con la estructura característica del estadio de predominio de las enfermedades infecciosas con altos registros de mortalidad en las edades extremas de la vida.

\section{Periodo crítico, mortalidad en 1918}

El 23 de octubre de 1918, en el periódico La Linterna de Tunja, aparece la primera mención sobre el impacto de la pandemia de gripa que según el periódico, en el momento, afectaba a cerca de cuatro mil habitantes de la ciudad que contaba, según el censo realizado en ese año, con 10.680 habitantes, 5.532 mujeres y 5.148 hombres.

Tunja, en temporada de lluvias, se paraliza por los efectos de la pandemia. La gripa: "ha aparecido en la ciudad con caracteres alarmantes. En menos de diez días, más de las dos quintas partes de la población ha sido atacada". El Batallón no ha podido montar guardia en los últimos días; en el Panóptico existen más de 190 casos y suspenden actividades por la gripa las Escuelas Normales, el Seminario y los colegios de la ciudad "que cuentan con numerosos casos". En el resto de la población, "no hay casa que no tenga enfermos" ( $\mathrm{La}$ Linterna, 23 oct. 1918).

En el informe oficial se consigna en una fecha mucho más tardía la vía de llegada de la gripa a la ciudad Tunja, donde predominaron las complicaciones pulmonares: "llegó la gripa a fines de octubre, y según el director de higiene se comprobó que fue introducida a Tunja por peones carreteros que llevaron la infección de Bogotá; pronto se propagó a todo el departamento, y como era natural, en los climas fríos predominaron las complicaciones pulmonares" (Revista de Higiene, ago. 1919, p.283).

El periódico tunjano considera que "es natural que la epidemia se extienda a todo el departamento" y ofrece a sus lectores consejos: "Importa sobre todo mantener las vías digestivas en buen estado". Recomienda un purgante a base de sulfato de soda. Para la fiebre y las neuralgias, recomienda antipirina y clorhidrato de quinina; un jarabe para la tos; "bebidas calientes, limonadas, no hacer uso de alimentos sólidos durante el mal"; lavar la 
garganta con infusión de eucalipto o de té con limón. Y concluye: "si el enfermo escupe sangre, debe llamar al médico".

Aparecen también pequeños avisos publicitarios referentes a la gripa, pagados por la Droguería Central "que vende a los mismos precios de siempre. No ha alterado los precios a que vendían sus drogas y medicinas antes de la gripa"; en otro aviso, recomienda jarabe antitífico que, asegura, fue éxito en Panamá, pues a la gripa "pudo dominarla con éxitos sorprendentes".

En El Deber, aparecen tres noticias breves; una que ofrece, nada menos que en un taller de mecánica, una receta gratis contra la epidemia de gripa: "En el taller de mecánica del señor Eduardo Boada se suministra gratis una magnifica receta para combatir, en pocas horas, la epidemia de la gripa. Es evidente por qué su aplicación no ha fallado". Otra, informa que a causa de la epidemia de gripa muchos matrimonios se han tenido que aplazar en la ciudad y, la última, dice que el médico Manuel N. Lobo recomienda, a los atacados de la gripa, no tomar quinina (El Deber, 1 nov. 1918).

En el período de enero a septiembre de 1918 ocurrieron un promedio de 308 muertes mensuales ( $\mathrm{SD}=22.2$; IC95\%=290.93-325.06); en consecuencia, la tasa promedio mensual de mortalidad fue de 1.14 x 1.000 habitantes ( $\mathrm{SD}=0.081$; IC95\%=1.08-1.20).

Si el comportamiento de la mortalidad durante los primeros nueve meses de 1918 fue similar al del año anterior, el último trimestre presenta características singulares que son las que ameritan un análisis separado. A partir de octubre, la mortalidad se eleva por encima del promedio, registrándose la mayor tasa en noviembre (5.6 x 1.000 habitantes). Las enfermedades respiratorias agudas y la gripa son responsables por el $52,6 \%$ de la mortalidad, mientras que las enfermedades gastrointestinales agudas y cardiovasculares aportan en conjunto $19,3 \%$ y las causas mal definidas, el 10,1\%

Los grupos de edad más afectados fueron el de los menores de un año, con una tasa global de 121.7 x 1.000 y el de los mayores de sesenta años con 66.5 x 1.000 habitantes, aunque, en términos absolutos, el mayor número de muertes ocurrió en los grupos de 15 a 44 años y en el de los mayores de sesenta años (1.412 y 1.131, respectivamente). Es importante anotar que las tasas específicas de mortalidad por grupo de edad registran aumentos sustanciales si se las compara con las del año 1917, especialmente el grupo de menores de un año que asciende de 93.4 a 121.7 por cada 1.000 niños (30,3\% de aumento); el de un a cuatro años que aumenta de 19.4 a 26.18 (35\% de incremento) y el de mayores de sesenta años que se incrementa de 60.4 a 66.5 x 1.000hab. (10,1\% de aumento).

En el último trimestre de 1918, se registran tasas mensuales de mortalidad superiores al promedio. Llama la atención la elevada mortalidad ocurrida durante el mes de noviembre, cuya tasa global es 4.93 veces superior al promedio mensual del período de enero a septiembre. La gripa constituye casi la mitad de todas las muertes y junto con las enfermedades respiratorias agudas copa un $72,2 \%$ de la mortalidad. Durante todo el período la tasa específica de mortalidad asciende a 4.26 por cada 1.000 habitantes, lo que constituye sólida evidencia de la presencia de un brote epidémico (Gráfica 2).

Un total de 16 defunciones por gripa se registran entre el 21 y el 31 de octubre de 1918, localizadas geográficamente en: Sugamuxi, cinco (Firavitoba, tres; Iza, un y Sogamoso, un); Márquez, cinco (Turmequé); Valle de Tenza, dos (Garagoa) y en el centro del departamento, cuatro (Tunja). Las defunciones corresponden a diez hombres y seis mujeres; 
Gráfica 2: Tasas mensuales de mortalidad por todas las causas en la población estudiada (ene. 1917-dic. 1920)

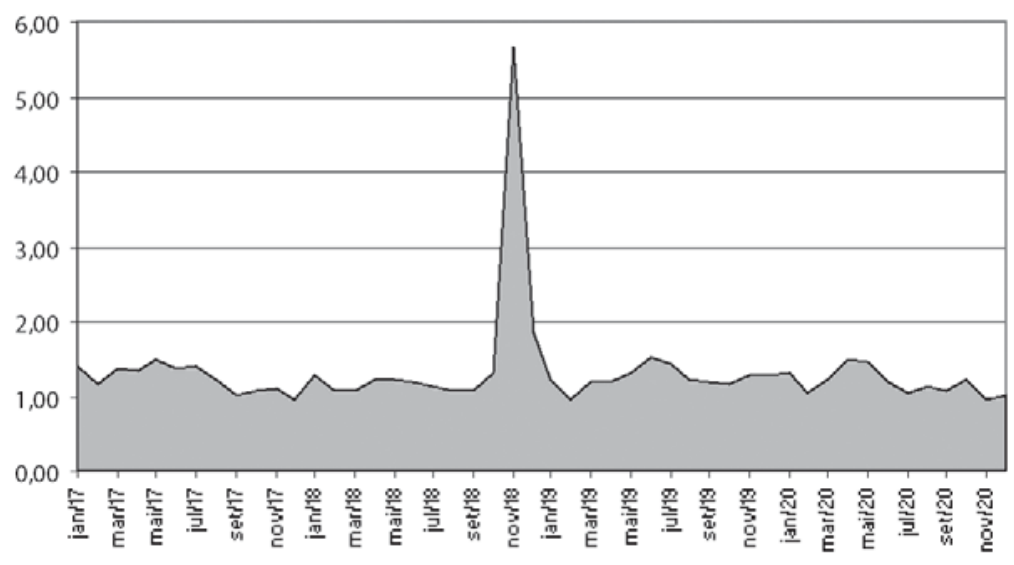

ocho adultos, seis menores de cinco años y dos de edad no determinada. El mayor impacto de la letalidad se focaliza en Turmequé que registra, en el lapso de cinco días, igual número de defunciones. Tres de los fallecidos tienen el mismo apellido (Carrasco) y provienen del área rural.

En la primera semana de noviembre, sobre un total de cien defunciones, se aprecia que la mortalidad por gripa se dejó sentir con mayor intensidad en los municipios del centro y el oriente del departamento.

Durante la segunda semana de noviembre se registraron un total de 255 defunciones por gripa que se distribuyeron en 29 de los 41 municipios estudiados. La tasa global de mortalidad por gripa se incrementó de 0.36 x 1.000 a 0.94 x 1.000 habitantes. Los municipios más afectados por la mortalidad se localizaron en las provincias del centro de Boyacá, Sugamuxi, Tundama y Márquez.

Con un total de trescientos fallecimientos por gripa en la tercera semana de noviembre, la tendencia en alza de la tasa de mortalidad global se mantiene, aunque el gradiente de aumento tiende a suavizarse. Hacia esta quinta semana de epidemia, se observa una rotación de municipios afectados y las tasas de mortalidad se atenúan en los municipios de las provincias del centro y Márquez, mientras se observa la incorporación de tasas de mortalidad más elevadas en municipios que se localizan hacia el norte y oriente del departamento.

Para los últimos diez días de noviembre, se evidencia claramente una menor afectación de los municipios del centro del departamento y provincia de Márquez (Tunja, Cómbita, Sámaca, Toca, Cucaita, Turmequé, Jenesano, Nuevo Colón) y mayores tasas de mortalidad en el oriente y norte del departamento (La Paz, Tasco, Beteitiva, Pueblo Viejo, Monguí, Tota, Belén), hecho que sugiere el carácter migratorio de la pandemia.

En la primera semana de diciembre, la tasa global de mortalidad presenta un descenso radical, con mayor afectación de municipios como La Paz, Tasco, Beteitiva, Tibasosa, Iza, El Cocuy; y algunos municipios del centro no afectados previamente como Moniquirá y Villa de Leiva.

El análisis del comportamiento temporal de la mortalidad permite concluir que los municipios con mayores tasas de mortalidad por gripa (superior a 9.0 x 1.000hab.) se 
encuentran en promedio a 2.715 metros de altura sobre el nivel del mar; de igual manera, los municipios con menores tasas de mortalidad por gripa (menor a 2.0 x $1.000 \mathrm{hab}$.) se ubican en promedio a 2.262 metros de altura sobre el nivel del mar (Tabla 1). También es importante anotar que, si bien no es posible hablar de un caso índice, la distribución de las tasas específicas de mortalidad por períodos de entre siete y 11 días permite determinar al menos tres focos de origen simultáneo de las muertes por gripa a partir del 21 de octubre de 1918: oriente (Iza, Firavitoba y Sogamoso), centro y provincia de Márquez (Tunja y Turmequé) y el valle de Tenza (Garagoa).

En conjunto, durante el período crítico de la epidemia, los menores de cinco años aportan el 36\% de todas las muertes por gripa y el grupo de 15 a 44 años, un porcentaje similar. No obstante, la cuantificación de tasas específicas por grupo de edad muestra mayor afectación de los menores de un año y de los niños de un a cuatro años de edad. El tercer grupo de edad más afectado es el de los mayores de sesenta años, mientras que el grupo de 15 a 44 años registra una tasa de mortalidad ocho veces menor que la de los menores de un año.

Si bien los datos obtenidos de los registros parroquiales aportan información valiosa, en las fuentes primarias se encuentra evidencia de subregistro. Bajo el título "Las víctimas de la gripa", aparece publicada una lista de las "Defunciones en Tunja del 25 de octubre al 10 de noviembre de 1918" que registra un muerto diario desde el 25 al 31 de octubre, un total de siete en la primera semana de mortalidad, la última de octubre; llama la atención que los tres primeros y el quinto eran niños. El $1^{\circ}$ de noviembre, reporta dos muertes, una mujer y un niño; el día 2, reporta cinco muertes, una niña; el día 4, reporta cuatro muertes; el 5 de noviembre, cinco; el 6, uno; el día 7 reporta cuatro, una niña; el 8, seis muertes, una niña; el día 9, cuatro muertes, una niña y el 10 de noviembre una mujer muerta. En total, 39 muertes en 17 días, diez de ellas infantiles, 23 masculinas, 16 femeninas. Aclara el periodista que las víctimas de la gripa en Tunja son más, ya que los residentes en las zonas rurales fueron enterrados en los pueblos que la circundan: "No figuran aquí algunos muertos de veredas apartadas que han sido enterrados en municipios vecinos". Se insiste en que el impacto fue mayor en las áreas rurales que en la zona urbana y que atacó principalmente a los campesinos, obreros y a los pobres: "Las víctimas, casi todas son gentes del campo ... sus víctimas, el flagelo las escoge entre los trabajadores, las clases pobre e indigentes".

En el periódico oficial El Boyacense, publicado en Tunja, el director registra el fallecimiento de cuatro reclusos de la penitenciaría de Tunja en el mes de noviembre 1918 durante la epidemia de gripa. Ya La Linterna informaba de 190 reclusos afectados en la penitenciaría de Tunja: (1) Tiburcio Laya, venezolano de 38 años, muere el 2 de noviembre por "una fuerte gripa"; su cadáver es "llevado al cementerio" (El Boyacense, 9 nov. 1918); (2) Justiniano Lara, de Coper, de 25 años, muere en la penitenciaría el 11 de noviembre; no aparece el diagnóstico; (3) Posidio Vargas A., 36 años, agricultor de Vélez, muere de neumonía el 13 de noviembre en la penitenciaria; (4) Urbano Avendaño, de Buenavista, 26 años, muere "a consecuencia de una gripa en el Hospital de Caridad", el 15 de noviembre de 1918 (El Boyacense, 11 dic. 1918).

Es importante anotar que ninguna de estas muertes aparece registrada en los libros de defunción de las parroquias de Tunja que reportan en total 51 muertes con el diagnóstico de gripa en la ciudad. Sólo uno de ellos fallece en el Hospital de Caridad. Los otros tres, al parecer, mueren en la penitenciaría que contaba con una enfermería con 12 camas. En un 
Tabla 1: Tasas de mortalidad por gripa, por período y acumulada en 41 municipios de Boyacá (oct. 1918-ene. 1919)

\begin{tabular}{|c|c|c|c|c|c|c|c|c|c|c|c|c|c|}
\hline FECHA & $\mathrm{OCT} / 18$ & & NOVIE & MBRE/1\& & & & DICIEN & $\mathrm{BRE} / 18$ & & & ENERO/ & & \\
\hline $\begin{array}{c}\text { MUNICIPIO } \\
\left(\mathrm{HSNM}^{*}\right)\end{array}$ & $21-31$ & $1-7$ & $8-14$ & $15-21$ & $22-30$ & $1-7$ & $8-14$ & $15-21$ & $\begin{array}{l}22- \\
31 \\
\end{array}$ & $1-7$ & $8-14$ & $22-31$ & total \\
\hline SORA (2.600) & & 0,5 & 4,47 & 5,46 & 1,99 & 0,99 & & & & & & & 13,41 \\
\hline MONGUI (2.880) & & 1,05 & 4,92 & 2,81 & 3,51 & 0,7 & & & & & & 0,35 & 13,34 \\
\hline AQUITANIA (3.060) & & 0,90 & 3,51 & 1,60 & 3,61 & 0,40 & 1,10 & 0,60 & 0,60 & 0,10 & 0,30 & 0,20 & 12,92 \\
\hline $\operatorname{TASCO}(2.620)$ & & 0,18 & 0,88 & 3,53 & 4,58 & 1,59 & 0,35 & 0,35 & 0,18 & 0,18 & & & 11,82 \\
\hline LA PAZ (2.700) & & & & 0,25 & 5,72 & 2,73 & 0,99 & 0,75 & 0,99 & & & & 11,43 \\
\hline SORACA (2.942) & & 0,73 & 6,55 & 1,82 & 1,46 & 0,36 & & & 0,36 & & & & 11,28 \\
\hline BETEITIVA (2.600) & & & & 2,99 & 3,99 & 1,5 & & 0,5 & 0,75 & & & 0,25 & 9,98 \\
\hline CORRALES (2.478) & & 0,27 & 3,47 & 4,27 & 1,33 & 0,27 & & & & & & & 9,61 \\
\hline IZA (2.560) & 0,37 & 0,51 & 2,04 & 2,55 & 2,55 & 1,02 & & & & & & & 9,04 \\
\hline FIRAVITOBA (2.508) & 0,06 & 1,79 & 2,76 & 2,21 & 0,83 & 0,28 & & & & & & & 7,93 \\
\hline TURMEQUE (2.404) & 0,72 & 1,88 & 2,61 & 1,01 & 0,43 & 0,58 & 0,29 & 0,14 & 0,14 & & & & 7,8 \\
\hline TIBASOSA (2.390) & & & 3,05 & 1,41 & 1,17 & 1,17 & & & & 0,23 & 0,7 & & 7,73 \\
\hline LEYVA (2.200) & & 0,28 & 0,56 & 1,12 & 2,52 & 0,84 & 0,56 & 0,28 & 0,28 & & & & 6,44 \\
\hline TOTA (2.634) & & 0,17 & 0,17 & 2,4 & 3,43 & 0,17 & & & & & & & 6,34 \\
\hline DUITAMA (2.590) & & 0,21 & 0,83 & 2,08 & 2,5 & 0,21 & & & 0,1 & & & & 5,93 \\
\hline COMBITA (2.730) & & 0,2 & 1,6 & 2,4 & 1,2 & & 0,2 & & & & & 0,2 & 5,8 \\
\hline TUNJA (2.820) & 0,51 & 1,5 & 1,5 & 0,75 & 0,66 & 0,19 & 0,19 & & & & & & 5,3 \\
\hline EL COCUY (2.749) & & & & & 1,52 & 0,93 & 0,7 & 0,35 & 0,23 & 0,35 & 0,58 & 0,58 & 5,24 \\
\hline PAIPA (2.577) & & 0,47 & 1,78 & 1,5 & 0,75 & 0,28 & 0,28 & 0,09 & & & & & 5,15 \\
\hline STA ROSA (2.520) & & & 0,66 & 1 & 1,99 & 0,17 & 0,5 & & 0,33 & 0,33 & & 0,17 & 5,15 \\
\hline ARCABUCO (2.739) & & & 0,63 & 1,27 & 2,53 & 0,32 & & 0,32 & & & & & 5,07 \\
\hline SAMACA (2.665) & & 0,23 & 1,16 & 0,92 & 1,16 & 0,46 & & & & & & 0,23 & 4,16 \\
\hline $\begin{array}{c}\text { SOGAMOSO } \\
(2.570)\end{array}$ & 0,41 & 0,97 & 0,73 & 0,85 & 0,54 & 0,06 & 0,06 & & & & 0,5 & & 4,12 \\
\hline N. COLON (2.450) & & & 0,24 & 1,2 & 1,2 & & 0,24 & 0,48 & 0,24 & & 0,24 & & 3,84 \\
\hline CHIQUINQ (2.570) & & 0,44 & 0,53 & 1,07 & 0,98 & 0,27 & 0,04 & 0,13 & 0,18 & & 0,09 & 0,09 & 3,82 \\
\hline RAMIRIQUI (2.345) & & & 0,27 & 1,6 & 1,47 & 0,4 & & & & & & & 3,74 \\
\hline JENESANO (2.500) & & 0,15 & 0,59 & 1,03 & 1,48 & 0,3 & & & 0,15 & & & & 3,7 \\
\hline BELEN (2.695) & & & 0,19 & 0,19 & 2,63 & 0,38 & & & & & & & 3,39 \\
\hline NOBSA (2.388) & & & 1,79 & 0,3 & 1,19 & & & & & & & & 3,28 \\
\hline $\begin{array}{c}\text { MONIQUIRA } \\
(1.764) \\
\end{array}$ & & 0,08 & & 0,39 & 0,77 & 0,54 & 0,39 & 0,15 & 0,23 & 0,15 & 0,23 & 0,08 & 3,01 \\
\hline CIENEGA (1.610) & & & 0,21 & 1,03 & 1,03 & 0,21 & & & & & & & 2,46 \\
\hline OICATA (2.815) & & & & & 2,01 & & & & & & & 0,4 & 2,41 \\
\hline CHISCAS (2.419) & & & & & & 0,25 & 1,02 & 0,38 & 0,38 & & & & 2,03 \\
\hline TINJACA (2.180) & & & & 0,82 & 0,16 & 0,16 & & 0,49 & & 0,16 & & 0,16 & 1,95 \\
\hline SOATA (2.045) & & & & & 0,6 & 0,08 & 0,15 & 0,38 & 0,3 & 0,3 & & 0,08 & 1,89 \\
\hline GARAGOA (1.730) & 0,02 & & 0,1 & 0,91 & 0,3 & 0,1 & & & & 0,1 & & & 1,53 \\
\hline BOYACA (2.361) & & & & & 1,31 & & & & & & & & 1,31 \\
\hline TOCA (2.810) & & 0,22 & 0,22 & & 0,65 & & & & & & & & 1,09 \\
\hline CUCAITA (2.640) & & & & & 0,38 & & & & & 0,68 & & & 1,06 \\
\hline $\begin{array}{c}\text { CHITARAQUE } \\
(1.571) \\
\end{array}$ & & & & & 0,16 & 0,32 & 0,16 & & 0,16 & 0,16 & & & 0,96 \\
\hline TUTA (2.603) & & & & 0,21 & 0,21 & & & & 0,21 & & & 0,21 & 0,84 \\
\hline Total & 0,06 & 0,36 & 0,94 & 1,11 & 1,39 & 0,37 & 0,2 & 0,14 & 0,15 & 0,15 & 0,07 & 0,07 & 5,01 \\
\hline
\end{tabular}

* HSNM: altura sobre el nivel del mar.

** En color se destacan los períodos con mayor tasa de mortalidad. 
solo caso se informa que el cadáver fue conducido al cementerio, pero sin ser registrado como defunción en la parroquia. Igual sucede con cuatro mujeres y cinco hombres que fallecen con el diagnóstico de gripa entre el $1^{\circ}$ y el 30 de noviembre de 1918 en el Hospital de Caridad y uno remitido por la Sociedad de San Vicente de Paúl de Tunja, que tampoco aparece registrado en los libros de defunción de las parroquias, lo que le sumaría 13 muertes más a Tunja durante la pandemia de gripa de 1918 (Hospital..., 1915-1922).

\section{Respuesta del gobierno y de la sociedad a la pandemia}

En el periódico conservador "El Deber", publicado en Tunja el 8 de noviembre, se lee que la epidemia ha "hecho unas cuarenta víctimas hasta ahora" en la ciudad y que el gobernador de Boyacá, que se había posesionado el $1^{\circ}$ de octubre, había expedido un "magnífico decreto relativo a la epidemia reinante a fin de combatir el flagelo y reunir fondos para atender a la necesidades mas urgentes de los enfermos pobres" (El Deber, 8 nov. 1918).

Informa La Linterna (23 oct. 1918), la creación de la Junta de Socorros de Tunja, actor principal en la atención de la pandemia de gripa en la ciudad: "Parece que se ha organizado una Junta para atender a los muchos enfermos que no pueden comprar medicinas, ni siquiera tienen donde abrigarse". Sobre la actuación de las autoridades, tras llegar la pandemia, se afirma: "El señor alcalde ha dictado algunas medidas relacionadas con el aseo de casa y solares, tendientes a acabar con los focos de infección que puedan contribuir a la propagación de la epidemia que nos ha invadido" (La Linterna,1 nov. 1918).

Las acusaciones sobre la ineficiencia de la organización sanitaria departamental son muy graves: "La Dirección de Higiene Departamental ha debido establecer ya la defensa, dar órdenes sobre boticas, dispensarios, cuidados con los enfermos, etc., etc. Ni una palabra sobre el particular. ¿Qué hace la Dirección de Higiene? ¿Duerme acaso? Hasta su oficina no llega el clamor que levanta la racha de espanto que diezma la población boyacense".

Tres meses llevaba la Dirección de Higiene de Boyacá sin prestar servicio por haberse enfermado el doctor Reyes Archila, el director de higiene; el redactor opina que si "hubiera verdadera administración, el doctor Reyes ha debido ser reemplazado, por el tiempo de su imposibilidad, para que el departamento al ser invadido por infecciones como la actual, no quede sin tener quien organice la defensa y dicte todas las precauciones indicadas para combatir la epidemia".

Aparecen en La Linterna, el 15 de noviembre, nuevas críticas a la acción gubernamental ante la pandemia de gripa. El redactor del periódico liberal se pregunta:

¿Cuál es la actitud de nuestro gobierno ante al desastre? ¿Cómo lucha por salvar del desastre al pueblo trabajador? ¿Ha establecido dispensarios para que se den a los pobres las medicinas que necesitan? ¿Ha fundado hospitales? ¿Ha establecido Juntas de Sanidad en todo el departamento? ¿Cree acaso nuestro gobierno que basta y sobra con la cartilla que la Junta de Sanidad ha dado a la publicidad? ¿Está satisfecho con sus decretos de alcance puramente local? Creemos que no puede estar satisfecho, ni ha obrado en este caso como está obligado a obrar un gobierno que se precia de cristiano. Una cartilla y un decreto no bastan.

$\ldots$

Urge que nuestro gobierno tome medidas salvadoras del pueblo pobre; urge que, como el gobierno de Cundinamarca, nombre médicos de sanidad en todo el departamento: urge que 
en cada una de las poblaciones invadidas por la gripa establezca juntas de socorros, semejantes a la que se fundó en esta ciudad. Es un deber del gobierno el de favorecer de la miseria y de la muerte a sus gobernados. Y es un deber nuestro exigirlo en nombre de los desgraciados" ( $\mathrm{La}$ Linterna, 15 nov. 1918).

Aparece también en La Linterna una breve noticia telegráfica, titulada "Protesta", fechada en Bogotá el 5 de noviembre,y enviada telegráficamente a La Linterna, en Tunja, escrita por un estudiante de medicina y dirigida contra el rector del Colegio de Boyacá por la desconsideración que tuvo hacia los estudiantes del Colegio afectados por la gripa: "Como ex-alumno del Colegio de Boyacá y en mi carácter de estudiante de medicina, protesto proceder salvaje rector ... que a los alumnos de aquel establecimiento se les obligaba a presentar examen, aun cuando estuvieran con la gripa".

Disposiciones ministeriales ordenaron suspender los exámenes finales y mandar a los alumnos para sus casas: "A causa de la gripa y por disposición del Ministerio de Instrucción Pública se suspendieron los exámenes en estos establecimientos y a los alumnos se les expidió su certificado de acuerdo con el cómputo anual de aprovechamiento". El rector del Colegio de Boyacá, organizó, en plena pandemia de gripa, la sesión solemne de clausura de estudios del año, el 31 de octubre (El Deber, 1 nov. 1918).

En un número posterior de La Linterna (15 nov. 1818), se ratifican las denuncias contra los directivos del Colegio de Boyacá: "Cuando la epidemia de gripa invadió el colegio, ni el rector ni el vicerrector se asomaron nunca a los dormitorios a ver a los jóvenes en el estado en que se encontraban. Como el rector no fue a ver a los estudiantes, tuvo la incomprensión de decir que estaban enfermos de pereza. Y de ahí la orden cruel de reprobarlos si no se presentaban a examen. Muchos jóvenes tuvieron que levantarse en estado febricitante a presentar examen".

\section{La Junta Patriótica de Sanidad y la financiación contra la pandemia de gripa}

En su informe a la Asamblea de febrero de 1919, el secretario de gobierno de Boyacá consigna que a fin de combatir la pandemia de gripa en Tunja, que amenazaba tener proporciones alarmantes, como sucedía en Bogotá, el gobierno dictó el decreto 157, el 30 de octubre, en plena epidemia, por el cual se creó una Junta Patriótica de Sanidad, ad honorem, en la ciudad, presidida por el alcalde, médicos, vecinos y vecinas de la ciudad, con participación del obispo Maldonado Calvo:

Junta Patriótica de Sanidad, compuesta del alcalde como presidente, del personero municipal y de los señores doctor Manuel R. Vásquez, don Jesús Mariño y doctor Roberto González; esta Junta, asesorada de las importantes comisiones de señoras y caballeros designadas por el Ilustrísimo señor obispo, levantó suscripciones a los particulares y éstas como aquella trabajaron con infatigable celo, gran entusiasmo y verdadero espíritu de caridad cristiana y prestaron inmenso beneficio a las clases desvalidas que fueron especialmente atacadas por la epidemia (Gobernación de Boyacá, 1 feb. 1919).

El decreto, en sus considerandos se justifica, argumentando: "Que la acción oficial en las calamidades públicas es ineficaz sino se apoya en la acción individual de los buenos ciudadanos". Por eso crea la Junta Patriótica de Sanidad, que solo recibió del gobierno de 
Boyacá la suma de cincuenta pesos. El total de los recursos recaudados para atender la pandemia en Tunja fue de 704 pesos con cincuenta centavos, recursos que salieron "del corazón de los generosos", es decir, no del Estado sino de la caridad pública y que fueron recolectados por siete ciudadanos que se registran como recolectores:

\footnotetext{
El gobierno departamental tan solo pudo auxiliar a la Junta con la pequeña suma de cincuenta pesos oro debido a la escasez de recursos del tesoro público pero, tanto la Junta Patriótica de Sanidad, como las Juntas de Socorros, supieron tocar el corazón de los generosos y levantaron una suscripción que alcanzó la suma de setecientos cuatro pesos con cincuenta centavos oro, la cual, satisfizo innumerables necesidades (El Boyacense, 4 nov. 1918).
}

El sindicato del Ferrocarril del Nordeste otorga a la Junta de Socorros de Tunja cuatro veces más que lo aportado por el gobierno departamental: doscientos pesos oro como aporte para "los desvalidos de la ciudad" (La Linterna, 15 nov. 1918). El obispo Maldonado Calvo da una contribución de cien pesos oro. Tanto el Banco de Boyacá como los superiores del Seminario de Tunja contribuyen con veinte pesos.

La ley 35 de 1918, firmada por el presidente Marco Fidel Suárez, asignó la suma de cuarenta mil pesos para combatir la epidemia de gripa en todo el país, evitar la propagación y proteger a los enfermos pobres "que no puedan atender a su restablecimiento". De esta suma, el gobierno nacional adjudicó cinco mil pesos al departamento de Boyacá, a Cundinamarca se le señaló igual cantidad. Los otros departamentos, menos afectados, recibieron entre todos treinta mil. En febrero de 1919, terminada la epidemia en todo el departamento, Boyacá aún no había recibido ni un centavo de este auxilio, según lo informa el secretario de gobierno a la Asamblea Departamental.

El decreto del 30 de octubre dispone además que: "Todos los médicos oficiales del departamento están en el deber de prestar apoyo a la Junta Patriótica de Sanidad y de atender las indicaciones de ella" (El Boyacense, 4 nov. 1918).

\section{La rogativa}

Mientras el gobierno repartía cartillas educativas y la Junta Patriótica de Sanidad asumía el control y establecía las normas para mitigar el daño causado por la gripa en la ciudad, la Iglesia organizaba en Tunja una rogativa, es decir, una procesión de grandes dimensiones, a la que se convocó a toda la ciudadanía, que recorrió la ciudad de Norte a Sur y que, probablemente, aportó más a la difusión del virus de la gripa que a prevenir el contagio de la enfermedad.

En el periódico El Deber, publicado en Tunja, el 8 de noviembre, aparece una noticia con el título: "Rogativa para obtener del Señor que cese el azote de la peste que nos aflige," nos cuenta cómo el obispo Eduardo Maldonado Calvo, que no asistió a la procesión, organizó la salida de las imágenes de Cristo, de San Antonio y de San Roque, que habían mostrado su efectividad ante las pestes coloniales, acompañados por todos los fieles de la ciudad, como acción para implorar a la divinidad, el remedio de la contagiosa enfermedad y derrotar, con las milagrosas imágenes, "el flagelo de la peste":

De acuerdo con el ilustrísimo señor obispo se ha resuelto sacar de la iglesia franciscana hoy viernes, a las 3 de la tarde, una procesión de las imágenes del Santo Cristo, San Antonio y San 
Roque, la cual irá hasta el Parque Pinzón en donde los presos cantaran un salve; luego seguirá por la carrera que va al Panóptico hasta la esquina de Hotel Bolívar; seguirá por la calle sur de la catedral a tomar la plaza y continuará hasta el Parque de los Mártires. De ahí irá hasta la salida de Bogotá y regresará por el camellón de Santo Domingo. En estas circunstancias tan aflictivas, es de esperarse que ninguno de los habitantes de la ciudad dejará de acudir a esta procesión para implorar al señor el remedio de la contagiosa enfermedad que azota a todos los pueblos de la República. Las milagrosas imágenes de San Antonio y San Roque continuarán expuestas a la veneración de los fieles de la iglesia de San Francisco hasta que termine el flagelo de la peste.

El 15 de noviembre, en La Linterna, se duda que la pandemia de gripa pueda ser detenida con las rogativas; el redactor del periódico sugiere, más bien, medidas higiénicas para poder detenerla y critica nuevamente la actitud de las autoridades gubernamentales:

el mal se extiende por todo el departamento, no lo detienen rogativas a San Antonio, ni a San Roque, ni a Santa Rosalía, ni al Cristo; solo podrían detenerla medidas higiénicas, medicinas eficaces, cuidados científicos, intensa propaganda que vaya por todas partes ... Y nada de esto, exceptuando las rogativas, ha preocupado a nuestro gobierno; el pueblo va cayendo en las garras de la muerte sin que sus gobernantes se muestren siquiera impresionados por los infelices, víctimas todos de la ignorancia, de la pobreza en que se les tiene sumidos sistemáticamente.

El reportero de La Linterna (15 nov. 1918), en su crónica periodística, en la que se involucra directamente, evidencia el gran peso de las creencias religiosas en la población rural de la ciudad. Una mujer campesina lleva a su marido, muy enfermo por la gripa, a la iglesia, en medio de la rogativa organizada por el obispo Maldonado Calvo, negándose la mujer a llevarlo al hospital o la botica, según el periodista, "víctima de su ignorancia":

El domingo pasado encontramos en una de las calles de la ciudad a un campesino amigo nuestro, a quien traía casi arrastrando su esposa: el pobre hombre respiraba trabajosamente; su cara congestionada, sudorosa, tenía color violáceo, sus ojos encendidos por la fiebre no toleraban la intensa luz del sol y lagrimaban constantemente; tosía y escupía sangre ... la esposa nos dijo que lo llevaba a la iglesia para que se confesara. Llévelo al hospital primero, le rogamos .... No señores, contestó la esposa. El hombre está de muerte y lo llevo primero a la iglesia. Entre a esta botica, volvimos a rogar, le pagamos los remedios. Primero lo llevo a la iglesia, replicó la mujer creyente.

...

Pasaba la rogativa y entre el montón siguió la pareja que iba a la iglesia, antes que la botica. Inútil decir que el pobre campesino murió esa misma tarde sin un remedio, pero se confesó y pagó la esposa el entierro. Así todos mueren víctimas de su ignorancia, agarrotados por el terror a los castigos de ultratumba y no saben - buen cuidado se tiene de no enseñárseles respetar la vida.

\section{Comportamiento de la mortalidad después del periodo crítico 1919}

Durante este año ocurrieron un total de 4.140 defunciones $(19,75 \%$ menos que en 1918), lo cual arroja un promedio mensual de 345 (SD=38; IC95\%=320.856-369.144). El mayor número de defunciones se registra en los meses de junio y julio. Durante todo el año, la tasa de mortalidad acumulada fue de 14.73 , lo que arroja una tasa promedio mensual de 1.23 x 1.000 habitantes (SD=0.135; IC95\%=1.14-1.31). 
La tasa específica de mortalidad por gripa desciende del 5.01 por mil en 1918 a 0.68 por mil en 1919. La enfermedad respiratoria aguda se mantiene como primera causa de muerte, y la gripa se reduce sustancialmente, bajando del segundo al sexto lugar. En términos porcentuales, la gripa disminuye en un $80 \%$ como causa de muerte. Se registran, durante el año 1919, un total de 192 defunciones por gripa, de las cuales el 84\% ocurre en los primeros seis meses como consecuencia del declive progresivo de la ola epidémica que se inició en octubre del año anterior.

La enfermedad gastrointestinal aguda, las causas cardiovasculares y las mal definidas mantienen el mismo nivel de significación. Estas características permiten configurar el perfil epidemiológico característico de las poblaciones subdesarrolladas, aunque la gripa continúa representando un papel significativo como causa de muerte.

\section{Mortalidad general y por gripa en 1920}

Se registran, durante este año, un total de 4.192 defunciones, lo que arroja un promedio mensual de 349 ( $S D=48,767$; IC95\%=318.01-379.98). Para un total de población estimada en esta muestra de 291.315 habitantes, se encuentra que la tasa general es de 14.39 fallecimientos por cada mil habitantes (tasa promedio mensual $1.20 \times 1.000$; $\mathrm{SD}=0.17$; IC95\%+=1.0921.308). La mortalidad general más elevada ocurre durante el período de abril a mayo.

Las mayores tasas de mortalidad son atribuibles a las enfermedades respiratorias agudas, enfermedades gastrointestinales agudas, enfermedades cardiovasculares y causas mal definidas, las cuales en conjunto representan el $73 \%$ de todas las causas de muerte. La gripa es responsable del $5 \%$ de todas las muertes, con una tasa de $0.71 \times 1.000$ habitantes durante todo el período. Las otras causas de muerte codificadas mantienen los mismos niveles observados en los años anteriores, de representatividad porcentual y por tasa.

Ocurren durante este año, un total de 208 defunciones con diagnóstico de gripa, la mayoría de ellas (78\%), durante el primer semestre. El pico máximo de mortalidad por gripa se registra durante los meses de abril y mayo, coincidiendo con una elevación de la tasa de mortalidad general.

\section{Balance oficial de la pandemia}

El 15 de noviembre, bajo el título "La gripa en Tunja", se lee en La Linterna una crónica donde el reportero tunjano hace un balance sobre los efectos de la pandemia de gripa en la ciudad, que, como en Bogotá, afectó con mayor intensidad a los pobres, dejando cadáveres de hombres, mujeres y niños en las vías públicas. Impresionante relato que, por su importancia, es importante transcribir:

Aparentemente la gripa no hizo estragos en la ciudad ... porque las víctimas salieron, salen todavía de las clases humildes, de los que lloran en silencio a sus muertos, y no pueden pagar el llanto a la iglesia, y marchan a la fosa común envueltos en la indiferencia que los arropó durante la vida.

$\cdots$

El camino de la muerte ha sido transitado a toda hora en los últimos días por cortejos llorosos que llevan en hombros el cuerpo de un artesano pobre que murió solo en el rincón de su taller, o el cuerpo de un agricultor que, bajo la inclemencia de un sol quemante, cayó sobre 
los haces de trigo que segaba enfermo; o el de una pobre mujer que, agobiada por la carga, se desplomó en la vía de donde fue recogido su cuerpo muerto ya; o el de un niño que buscó amparo en el portalón de una casa y fue sorprendido allí por el sueño de la muerte. Y por las calles menos transitadas de la ciudad el desfile de cadáveres continúa sin que la ciudad misma se haya dado cuenta de la catástrofe.

$\ldots$

Hay que llegar al cementerio para poder darse uno cuenta de la magnitud del desastre; hay que detenerse a mirar la ruda faena de los enterradores, inclinados a toda hora sobre la tierra, abriendo fosas a la luz de los faroles ... . Sin embargo, decimos todos que la gripa no ha causado estragos ... . Olvidamos que cada uno de los muertos era un trabajador ..., que los brazos de aquel hombre sembraban el pan ... cuanto pierde un pueblo cuando los brazos útiles son segados así por la muerte. Sólo cuando venga el hambre comprenderemos todos que la gripa sí causó verdaderos estragos, llevándose a los humildes.

Tras visitar algunas poblaciones cercanas a Tunja, ubicadas en la provincia del centro, la más afectada, revela un panorama igual de desolador a causa de la pandemia de gripa: "No sabían luchar contra el flagelo; no tenían un remedio contra la enfermedad; iban por los caminos, por las calles, por los senderos arrastrando su dolor, febricitantes, expuestos al sol y a la lluvia, y en los caminos, en las calles, en los senderos, caían heridos por la muerte" (La Linterna, 15 nov. 1918).

Datos incompletos revelan 784 defunciones por gripa, que se presentaron en el mes de noviembre de 1918, en la provincia de Centro. Según el mensaje del gobernador de Boyacá a la Asamblea Departamental "hubo en la provincia, durante el mes de noviembre retropróximo, 784 defunciones, según los datos no muy completos recogidos hasta ahora, y el número de muertos hubiera sido mayor si tanto los particulares como el gobierno no hubieran aunado sus esfuerzos para combatir la enfermedad y evitar su contagio" (Gobernación de Boyacá, 1919).

En el informe que presenta, en 1919, el director nacional de higiene al ministro de instrucción pública, ministerio del que dependía, se resume el informe oficial de la pandemia de gripa de 1918 en Boyacá, donde causó 2.691 muertos, aunque se afirma a continuación que "no se pudo obtener dato sobre el total de defunciones por gripa".

A pesar de todo, y vista la densidad de la población, las defunciones no fueron tan numerosas como en Cundinamarca, pues alcanzaron, en todo el departamento, a 2.691. No se pudo obtener dato sobre el total de defunciones por gripa. El gobierno del departamento dictó providencias eficaces para que las autoridades atendieran los enfermos y proporcionó los recursos de que pudo disponer, y en la capital se organizó una junta que prestó grandes servicios (Revista de Higiene, n.115, ago. 1919, p.283).

El 22 de noviembre de 1918, La Linterna titula "La gripa se va" y usa la descriptiva metáfora "huyendo de la caridad ... mientras la higiene dormía el sueño profundo de la indiferencia:

En días pasados, seguimos a una de las comisiones de la Junta de Socorros, la comisión encargada de llevar alivio y consuelo al barrio alto de la ciudad" ... la chiquillería del barrio, apenas convaleciente, corría a recibir a las damas de la comisión; exhiben entre sus harapos las carnes amoratadas por el frío; las criaturas titiritaban sonrientes y, agarradas de las faldas de las señoritas, iban denunciando los dolores ocultos en aquellos escondidos rincones donde la peste había sentado sus reales 
$\cdots$

El resultado final de la visita de ese día fue consolador: la peste huía; la gripa abandonaba a la población; la caridad debía ahora atender más a los pobres hambreados que a los enfermos, y la comisión decidió fundar cocinas a donde pudieran acudir los necesitados ... La gripa se ha ido ya, y se ha ido huyendo de la caridad que por todas partes la persiguió, mientras la higiene dormía el sueño profundo de la indiferencia. Bendita tierra esta que da vida a grandes despropósitos: el gobierno sueña, la sociedad obra; la higiene duerme, la caridad vela .... Sin embargo vivimos.

La Linterna (22 nov. 1918) reconoce la labor de las comisiones de la Junta de Socorros de Tunja y del obispo Maldonado Calvo que abrió cocinas para alimentar a los pobres de la ciudad, igualmente el gremio obrero de Tunja organizó "una suntuosa manifestación" en la ciudad "en honor de la Junta de Socorros para hacerle presente su agradecimiento por la manera generosa y eficaz como auxilió a todas las clases proletarias durante el tiempo que la gripa visitó la ciudad".

En el Informe del director de higiene, doctor Carlos Reyes Archila, a la Asamblea, de 1919 sobre la pandemia de gripa, quien se califica como una de las primeras víctimas de la enfermedad, informa que carece de datos sobre mortalidad en Tunja, la que califica de "poca", y afirma que su oficina solo se limitó a divulgar material educativo que le enviaron de la Junta Central de Higiene en Bogotá:

A mediados de mes de octubre y en el mes de noviembre, la epidemia de gripa ... invadió a esta ciudad y a casi todos los municipios del departamento, con tales caracteres de infección y mortalidad que desde el primer momento alarmó ... . De sus primeras víctimas fue el suscrito, de manera que la Dirección de Higiene quedó privada de su misión y solo se ocupó la oficina en la distribución y envío de las instrucciones y cartillas higiénicas y de profilaxis que oportunamente la Junta Central de Higiene repartió profusamente (Gobernación de Boyacá, 1919).

El director de higiene ratifica que la atención de los afectados por la pandemia de gripa estuvo en manos de la Junta Patriótica de Sanidad, creada en Tunja por el gobernador, convocando a los miembros de la elite, a las autoridades municipales y eclesiásticas, a finales de octubre de 1918. Concluye que en Tunja la gripa tuvo alta morbilidad y poca mortalidad:

Usted señor gobernador se apresuró a constituir en esta ciudad una junta que se llamó Junta Patriótica de Sanidad ..., encargada de auxiliar a los desvalidos atacados por la gripa; coadyuvar a la labor de las corporaciones oficiales; de dictar las medidas conducentes para evitar la propagación de la epidemia; y de solicitar y arbitrar recursos del Consejo Municipal y de los particulares. La acción de la junta pronta y eficaz, secundada intensamente por la alta sociedad de Tunja, logró la pronta extinción de la epidemia en la ciudad, donde la enfermedad si bien atacó muchas personas causó poca mortalidad (Libro de informes del gobernador de Boyacá a la Asamblea Departamental. Informe del director de higiene, Tunja, 1919).

\section{Discusión}

Pese a que los registros de defunción de los libros parroquiales ofrecen un recuento de mortalidad que permite esbozar el perfil epidemiológico, es importante anotar que el análisis 
de otras fuentes primarias, como los periódicos y libros hospitalarios, constituyen, en el caso particular de Tunja, evidencia de subregistro durante el período crítico de la pandemia. Es el caso de 13 defunciones, ocurridas en la penitenciaria y en el Hospital de Caridad, que no se encuentran registradas en los libros de ninguna de las tres parroquias de la ciudad. Para este caso, se encuentra que 20,34\% de las muertes por gripa, hasta ahora registradas en esta ciudad, no se incluyeron en la base de datos analizada.

No obstante, la información recopilada permite confirmar la ocurrencia de una epidemia de gripa que se desarrolló desde mediados de octubre de 1918 y se prolongó hasta agosto de 1919, con un pico máximo de mortalidad durante el mes de noviembre. El análisis cronológico permite apreciar, además, en los meses de enero de 1920 hasta agosto del mismo año, un incremento significativo de los casos absolutos de muertes por gripa en la muestra de municipios estudiada, notablemente inferior a la pandemia de 1918, pero significativamente mayor que las muertes de carácter estacional registradas en los períodos previos (Gráfica 3). La información disponible hasta el momento no nos permite concluir que este incremento de mortalidad por gripa se corresponda con una oleada final de la pandemia de 1918. Tampoco es posible precisar la existencia de tres oleadas, como se describe en la literatura de Europa y Estados Unidos.

Por fecha, se encuentran por lo menos dos focos de inicio de la mortalidad atribuible a la pandemia en 1918: Uno en Turmequé y Tunja (distantes uno del otro $45 \mathrm{~km}$ ) que reportan un total de nueve fallecimientos. El segundo, en la provincia de Sugamuxi que compromete los municipios de Iza, Firavitoba y Sogamoso. Las otras dos defunciones ocurren en Garagoa, población de clima templado, distante unos $80 \mathrm{~km}$ de Tunja. La ubicación geográfica de estos primeros casos de mortalidad invita a pensar que el contagio se transmitió desde Bogotá (donde la epidemia tuvo máximo rigor en octubre) a las poblaciones vecinas a la Carretera Central del Norte, inaugurada en la primera década del siglo XX (Figura 2). Esto confirma lo reportado por las autoridades sanitarias del departamento en los reportes y balances de la época.

Aunque en sentido estricto, el riesgo atribuible a la exposición se define como la diferencia de riesgo entre sujetos expuestos y no expuestos, en el caso particular de una epidemia, en la que la única información disponible es la mortalidad, el riesgo atribuible se estima a partir de la diferencia de riesgos de morir a causa de la gripa en comparación con el riesgo previamente conocido de morir por otras causas.

Durante los quatro años estudiados, se ha podido estimar la tasa mensual de mortalidad por cada mil habitantes, la cual es en promedio $1.3 \times 1.000$ (SD=0.658; IC95\%=1.1191.501) muertes mensuales. Excepto el período de octubre de 1918 a enero de 1919 no se aprecian grandes fluctuaciones en la magnitud de estas tasas (Gráfica 2). En consecuencia, es factible asumir una tasa esperada de mortalidad para el período la cual asciende a 1.34 meses $=5.2$ por mil habitantes. La tasa real que ocurrió fue de $10.08 \times 1.000$, con lo cual tenemos que la tasa de riesgo atribuible a la exposición que se ilustra en la gráfica $\mathrm{n}$. 5 es de $10.08-5.2=4.88 \times 1.000$ habitantes.

El riesgo atribuible expresa la cantidad de casos que no hubieran ocurrido en ausencia del contagio. Para este caso, esa cifra ascendería a unas 1.296 muertes en la muestra estudiada. Si este riesgo atribuible se extrapola a la población total estimada de Boyacá a finales de 
Figura 2: Localización de los primeros casos de mortalidad por gripa (21-31 oct. 1918)

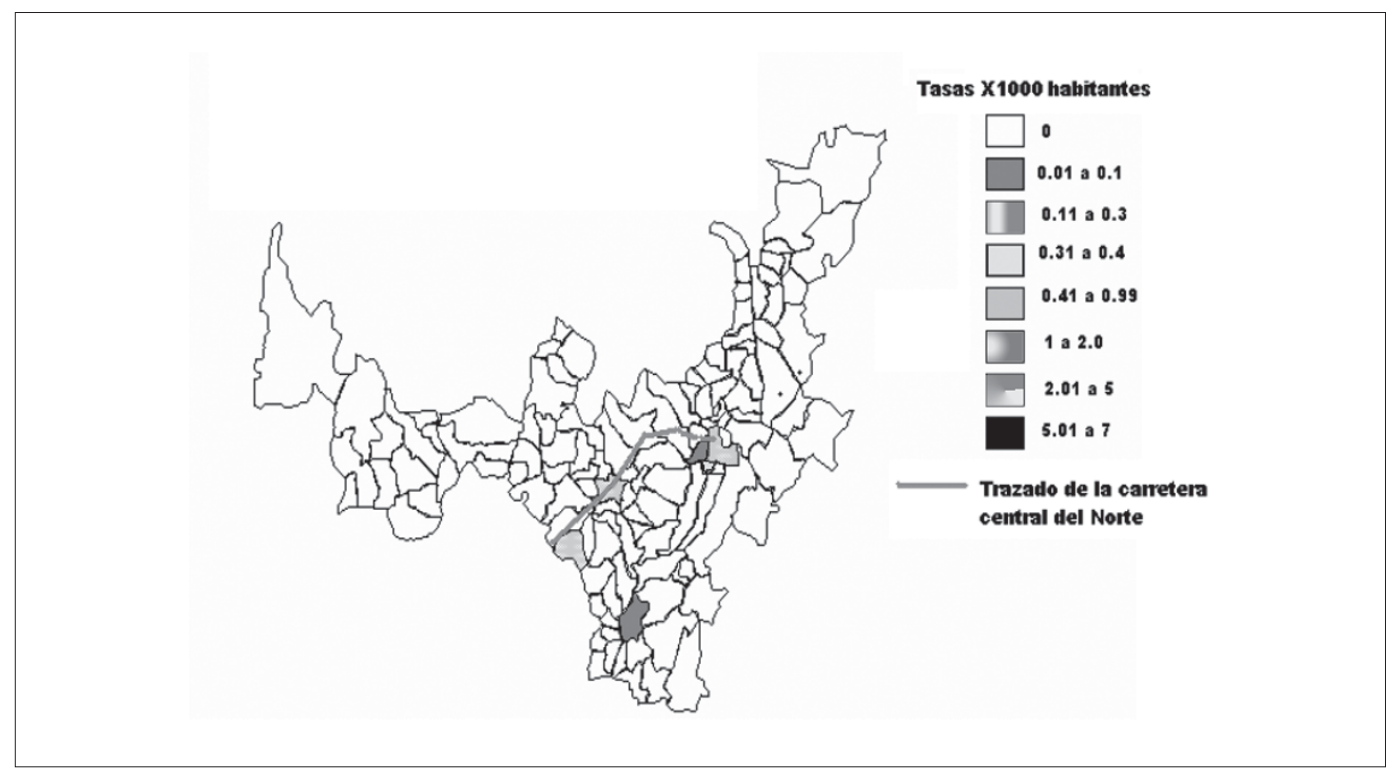

Gráfica 3: Muertes mensuales por gripa en 41 municipios de Boyacá (ene. 1917-dic. 1920)

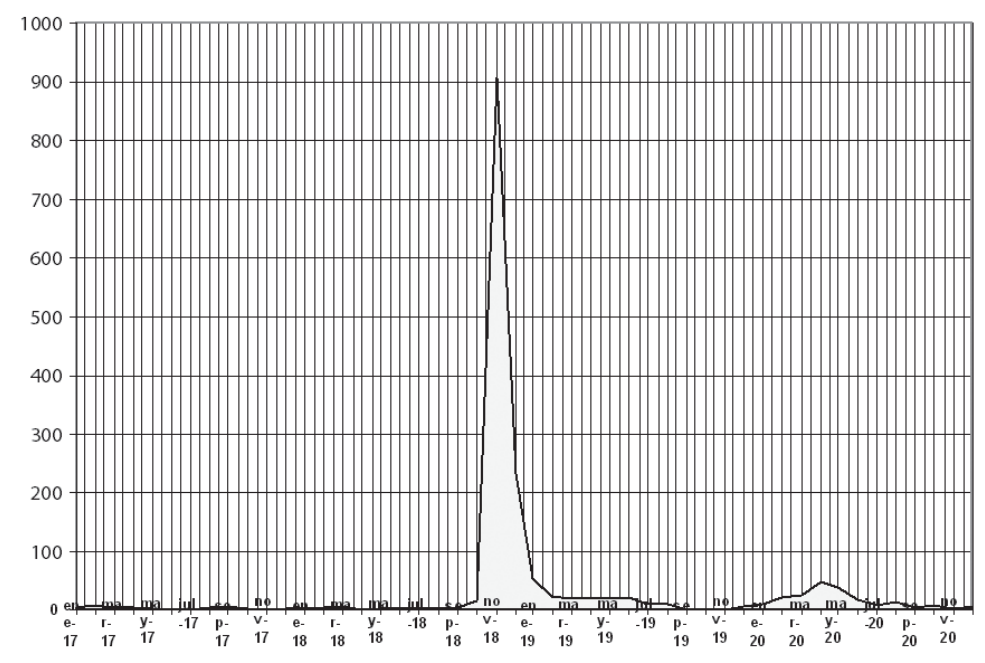

1918, podríamos decir que ocurrieron alrededor de 2.875 fallecimientos como consecuencia de la gripa.

Buscando hacer una aproximación al concepto del análisis de tipo ecológico, la estimación de los factores de riesgo que se pudieron determinar en relación de la probabilidad de morir a causa de la gripa se resume en la Tabla 2.

A partir de este análisis bivariado se estructuró un modelo de regresión lineal que demostró que las variables grupo de edad extremo (menor de cinco años o mayor de sesenta), altura sobre el nivel del mar, habitar en zona rural y densidad poblacional del municipio ajustaron con un coeficiente de determinación $\mathrm{r}^{2}=0.83$. 
Sobre los inicios de la pandemia en Boyacá, las fuentes primarias registran que

a la capital de Boyacá llegó la gripa a fines de octubre y según el director de higiene se comprobó que fue introducida a Tunja por peones carreteros que llevaron la infección de Bogotá; pronto se propagó a todo el departamento y, como era natural, en los climas fríos predominaron las complicaciones pulmonares. A pesar de todo y vista la densidad de la población, las defunciones no fueron tan numerosas como en Cundinamarca, pues alcanzaron en todo el departamento a 2.691 (Revista de Higiene, Bogotá, n.115, ago. 1919).

La expansión de la mortalidad, que en el breve lapso de una semana pasó de ubicarse en seis municipios para luego extenderse a 21 de los 41 estudiados y en dos semanas más llegó a los cuarenta, algunos de ellos distantes más de $200 \mathrm{~km}$ de los focos iniciales, deja expresa constancia de la extraordinaria virulencia y letalidad del agente causal. El mes de noviembre de 1918 fue el escenario temporal para la expansión de la epidemia, a una velocidad particularmente elevada, que acusó índices de mortalidad diferenciales, de manera que la tasa de mortalidad atribuible a la gripa oscila, en los 41 municipios estudiados, en un rango que va desde 13.41 por mil habitantes en Sora, hasta 0.84 en Tuta, con una tasa global de 5.01 por mil en la muestra de municipios estudiados (Tabla 1).

Tabla 2: Factores de riesgo asociados a la probabilidad de morir a causa de la gripa en 41 municipios de Boyacá entre octubre y diciembre de 1918 (OR=Odds ratio)

\begin{tabular}{|l|l|c|c|}
\hline \multicolumn{1}{|c|}{ FACTOR } & OR* & IC 95\% & P \\
\hline Menor de 5 años & 3.71 & $3.29-4.19$ & $<0.0001$ \\
\hline Mayor de 60 años & 1.62 & $1.35-1.95$ & $<0.0001$ \\
\hline Menor de 5 años o mayor de 59 & 3.49 & $3.1-3.92$ & $<0.0001$ \\
\hline Residente en el área rural & 1.67 & $1.4-2.0$ & $<0.0001$ \\
\hline Población localizada por encima de los 2000 mts. SNM & 1.68 & $1.36-2.07$ & $<0.0001$ \\
\hline Población con menos de 64 habitantes por km ${ }^{2}$ & 1.30 & $1.16-1.47$ & $<0.0001$ \\
\hline Género & 0.97 & $0.88-1.08$ & 0.60 \\
\hline Municipio expuesto previamente a virus gripales & 0.96 & $0.85-1.07$ & 0.43 \\
\hline
\end{tabular}

* OR: Odds ratio.

Se encuentra una asociación estadísticamente significativa en la relación entre el riesgo de morir por causa de la gripa y la altura sobre el nivel del mar del municipio. En el análisis multivariado, se establecieron puntos de corte diferenciales, encontrando un gradiente positivo para la Odds Ratio (OR) que permite establecer que la probabilidad de morir a causa de la gripa, durante el período crítico de la pandemia, se incrementa desde un OR de 1.68 a partir de los 2.000m.s.n.m. hasta 3.64 por encima de los 2.800metros (Gráfica 5). Este resultado sugiere que el volumen de oxígeno atmosférico disponible, en función del piso térmico, es determinante en la evolución y propagación del cuadro clínico de la gripa, en particular de las formas severas.

Concuerdan los estudios conocidos sobre la gripa en afirmar que, en Norteamérica y Europa, el grupo de edad más diezmado por la mortalidad pandémica fue el comprendido entre los veinte y los cuarenta años de edad (Echeverri Dávila, 1993, p.IX; Crosby, 2003, p.202-226) y que en los grupos de edad extremos (menores de cinco años y mayores de 
Gráfica 4: Muertes diarias por gripa y todas las causas en 41 municipios de Boyacá (1 oct.-31 dic. 1918)

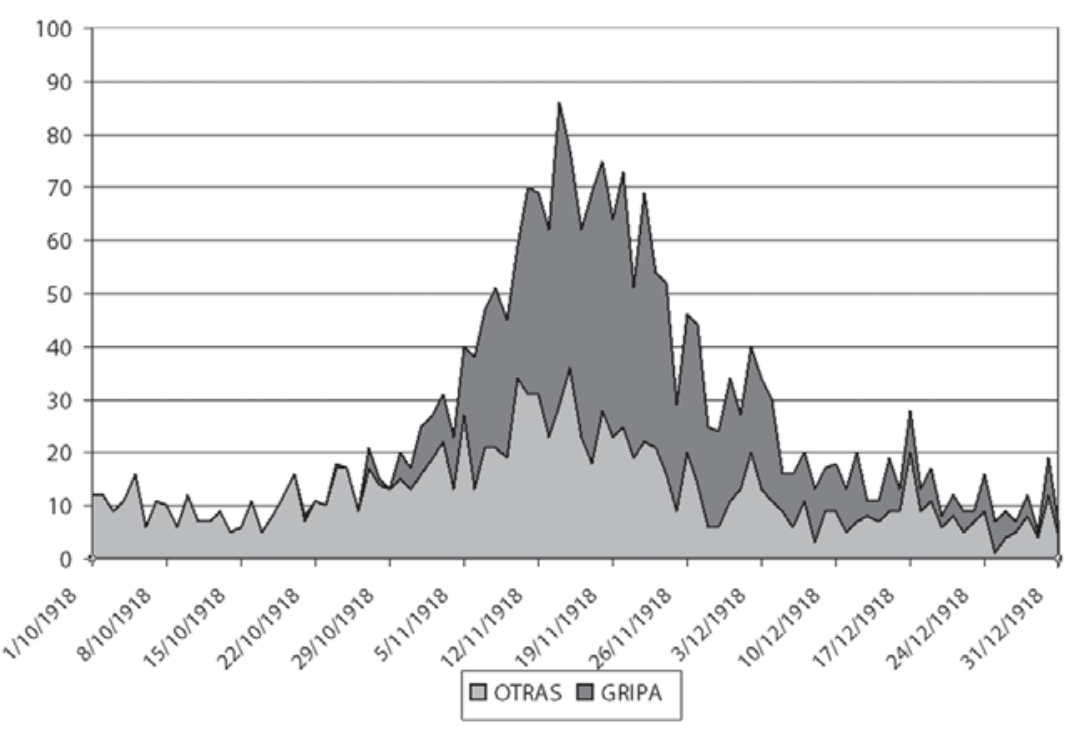

Gráfica 5: Relación entre la altura sobre el nivel del mar (HSNM) y la probabilidad de morir a causa de la gripa expresada como Odds Ratio (OR)

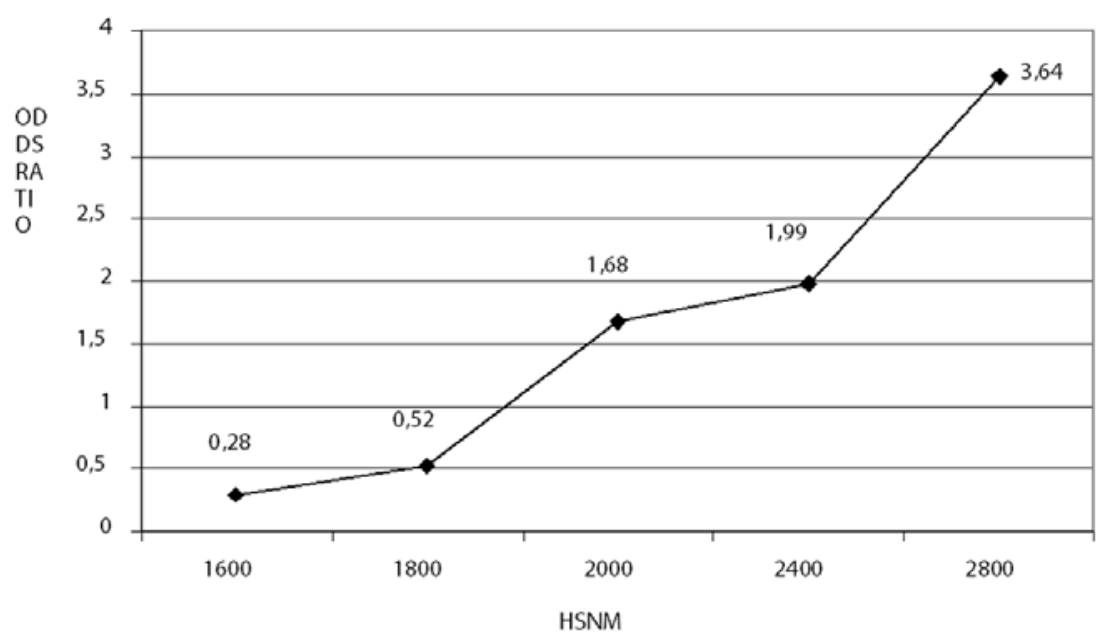

sesenta) se registra, de manera un tanto anormal, una baja proporción de muertes (Echeverri Dávila, 1993, p.47). En la muestra estudiada en Boyacá, si bien es cierto que el número absoluto de muertos es mayor en el grupo de personas en edad productiva, las tasas específicas de mortalidad demuestran, sin lugar a dudas, que el grupo de edad más afectado fue el de los menores de cinco años, seguido por el de los mayores de sesenta años (Gráfica 5). Por otra parte, el análisis bivariado que establece el riesgo de morir a causa de la gripa, si se encuentra en uno de los grupos extremos de edad, comparado con el riesgo del grupo de edad comprendido entre los cinco y los 59 años, refleja un riesgo 3.39 veces mayor (IC95\%=3.013.82; $\mathrm{p}<0.0001$ ). Este aspecto reviste importancia en el posterior comportamiento demográfico por cuanto no se afectó el grupo poblacional en edad reproductiva. 
En relación con el género, no se encuentra en la muestra analizada una afectación o riesgo diferencial para la probabilidad de morir si se contraía la gripa $(\mathrm{OR}=0.97$; IC95\%=0.88-1.08).

La evaluación de la asociación entre el riesgo de morir como consecuencia de la gripa, comparando el sitio de residencia urbano o rural, expresa que la probabilidad de morir al contraer la gripa, si se vivía en el campo, era mayor ( $\mathrm{OR}=1.67$; IC95\%=1.4-2.0). Es importante anotar que para esta época el 70\% de la población se localizaba en áreas rurales.

\section{Conclusiones}

A partir de la consolidación de un modelo de economía capitalista, interesado en la industrialización y exportación, bajo la égida del proceso político conocido como la hegemonía conservadora, el departamento de Boyacá entró, desde comienzos del siglo $\mathrm{XX}$, en un proceso de relegación y pérdida de significación política en el contexto nacional.

Para la segunda década del siglo XX, la condición higiénica y sanitaria de los conglomerados urbanos y rurales del departamento de Boyacá era insuficiente e inadecuada, lo que determina el predominio de enfermedades infecciosas en el perfil de mortalidad general.

Durante los años de 1912 a 1917, la gripa, no atribuible al subtipo H1N1 de 1918, era una causa de muerte presente en el departamento de Boyacá, más frecuente en el piso térmico frío, y es posible reconocerla, en algunos municipios, como una patología de carácter estacional con mayor mortalidad en los períodos lluviosos.

Contrario a lo reportado en la literatura especializada de Europa y Norteamérica, no se registran tres oleadas de la pandemia conocida como spanish flu en la muestra estudiada en el departamento de Boyacá. El aumento de casos de mortalidad por gripa, ocurrida entre enero y agosto de 1920, amerita una indagación exhaustiva en una muestra de municipios mayor y ampliando el período de estudio que se está desarrollando (Gráfica 3).

La pandemia de gripa se inició a comienzos de octubre en Bogotá y rápidamente se extendió al departamento de Boyacá, a través de la Carretera Central del Norte. Los primeros municipios afectados en la muestra estudiada se encuentran sobre el trazado de esta vía o muy próximos (Turmequé, Tunja, Sogamoso, Garagoa, Iza y Firavitoba), lugares en donde en el período comprendido entre el 21 y el 31 de octubre se registran las primeras defunciones (Figura 2).

El comportamiento de la onda epidémica durante la primera oleada es el característico de las enfermedades infecciosas agudas, registrando altas tasas de contagio en el primer mes, que posteriormente decrecen en la medida en que se agota la población de susceptibles.

Durante el período crítico, comprendido entre octubre de 1918 y enero de 1919, la tasa específica de mortalidad por gripa, en la muestra estudiada, alcanzó a ser de 4.8 por mil habitantes. Si se proyecta este estimado a la población general del departamento de Boyacá para el año de 1918 (58.6000 habitantes), se calcula que la epidemia ocasionó aproximadamente 2.800 defunciones durante este lapso.

Pese a que en los reportes de estudio de la epidemia, realizados en países europeos y algunos de Norteamérica, describen, en términos absolutos, como caso atípico una mayor mortalidad en el grupo de edad comprendido entre los veinte y los cuarenta años, al comparar, no en números absolutos sino a través del análisis de tasas específicas de 
mortalidad por grupo de edad y tasas específicas de ataque, en el presente estudio se demuestra que la gripa afecto, en Boyacá, en muchísimo mayor grado a los menores de cinco años y a los mayores de sesenta (Gráfica 6).

Gráfica 6: Tasas específicas de mortalidad por gripa según grupo de edad en 41 municipios de Boyacá (oct.-dic. 1918)

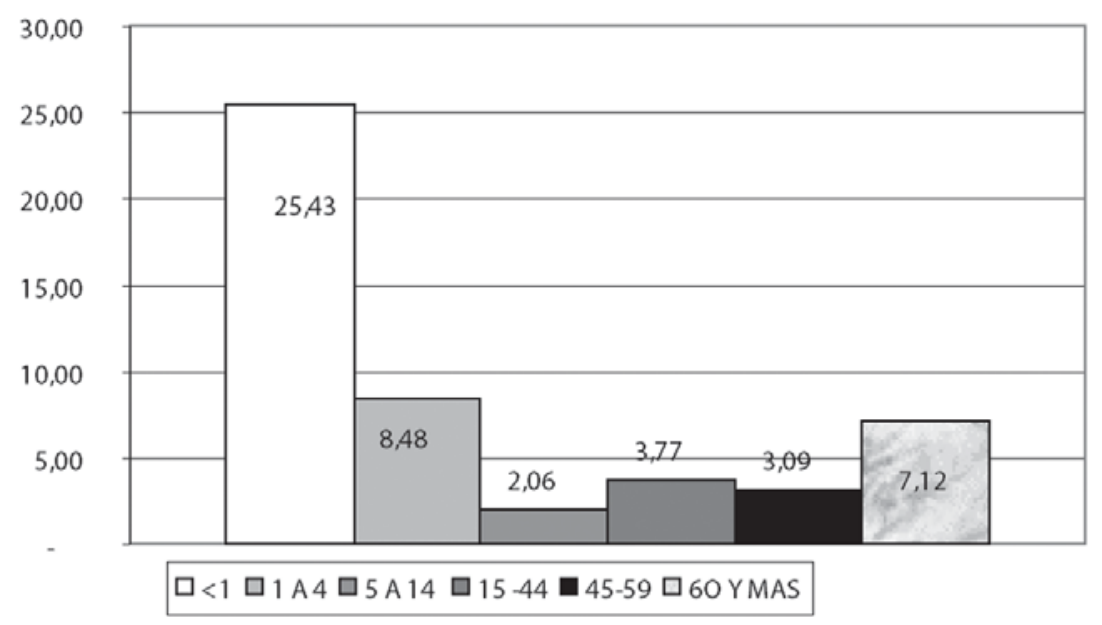

Se encontró que el piso térmico fue un factor que incidió en la probabilidad de morir si se contraía la gripa. Esta probabilidad, expresada como Odds Ratio (OR), registra un gradiente positivo que va desde 0.28 a los $1.600 \mathrm{mts}$. hasta 3.64 por encima de los $2.800 \mathrm{mts}$. (Tabla 2). Un ejemplo interesante es la comparación de las tasas globales de mortalidad ocurridas durante el período crítico entre los municipios de Aquitania, localizado en piso térmico páramo (3.050m.s.n.m., temperatura promedio de $\left.11^{\circ} \mathrm{C}\right)$, que registró una tasa de 28.18 por mil habitantes, que contrasta con la de Tinjacá, municipio situado en piso térmico frío (2.100m.s.n.m., temperatura promedio de $\left.16^{\circ} \mathrm{C}\right)$, que registró para el mismo período una tasa de 7.52, casi cuatro veces menor a la del primer municipio. Entre los dos hay una diferencia de altura de $950 \mathrm{~m}$ y de $5^{\circ} \mathrm{C}$ de temperatura promedio.

También se encontraron como factores de riesgo asociados a la probabilidad de morir si se contraía la gripa, el lugar de residencia, siendo más afectados los habitantes de las áreas rurales $(\mathrm{OR}=1.67)$, y la densidad poblacional, si se contraía la gripa en los municipios menos densamente poblados (menos de 64 habitantes por $\mathrm{km}^{2}$; OR=1.30) (Tabla 2).

El registro de las tasas brutas de mortalidad muestra que, después de la ciudad de Bogotá, el departamento de Boyacá fue la región más afectada, en términos de mortalidad, por la epidemia de gripa; esto en comparación con los departamentos y regiones en los que se obtuvo información en fuentes de la época (Tabla 3). 
Impacto de la pandemia de gripa de 1918-1919...

Tabla 3: Datos de morbilidad, mortalidad y letalidad de la pandemia de gripa (Colombia, 1918)

\begin{tabular}{|l|c|c|c|c|c|c|}
\hline \multicolumn{1}{|c|}{ DEPTO. } & POBL. & ENF. & MUERTOS & $\begin{array}{c}\text { MORBILIDAD } \\
(\times 1.000 \text { HAB. })\end{array}$ & $\begin{array}{c}\text { MORTALIDAD } \\
(\times 1.000 \text { HAB. })\end{array}$ & $\begin{array}{c}\text { LETALIDAD } \\
(\mathrm{x} 100 \text { HAB. })\end{array}$ \\
\hline BOGOTA & $125.000^{1}$ & & $1.262^{2}$ & & 10.09 & \\
\hline BOYACA & 659.947 & & 2.691 & & 4.07 & \\
\hline VALLE & 271.547 & 56167 & 678 & 20.68 & 2.49 & 1.20 \\
\hline CALDAS & 427.906 & & 1.006 & & 2.35 & \\
\hline TOLIMA Y HUILA & 501.544 & & & & $2.0^{3}$ & \\
\hline SANTANDER & 429.144 & 35303 & 706 & 8.22 & 1.64 & 1.99 \\
\hline ANTIOQUIA & 828.125 & 113225 & 776 & 13.67 & 0.93 & 0.68 \\
\hline NORTE SDER. & 239.217 & & & & $0.5^{3}$ & \\
\hline NARIÑO & 340.759 & & & & & $2.0 \%$ \\
\hline
\end{tabular}

\section{REFERENCIAS}

ABRÃO, Janete Silveira.

Banalização da morte na cidade calada: a hespanhola em Porto Alegre, 1918. Porto Alegre: EDIPUCRS. 1998.

ARCILA, Mauricio.

Cultura e identidad obrera: Colombia, 19101945. Bogotá: Cinep. 1991.

AYORA-TALAVERA, Guadalupe. Influenza: historia de una enfermedad. Biomédica, Bogotá, n.10, p.57-61. 1999.

BARRY, John M.

The great influenza: the epic story of the deadliest plague in history. New York: Penguin Books. 2004.

BENNETT, J.C.; PLUM, F.

Cecil textbook of medicine. 20. ed. Philadelphia: W.B. Saunders Company. 1996.

BERNABEU MESTRE, Josep (Coord.).

La ciutat davant el contagi: Alacant i la grip de 1918-19. Valencia: Conselleria de Sanitat i Consum. 1991.

BERTOLLI FILHO, Claudio.

A gripe espanhola em São Paulo, 1918: epidemia e sociedade. São Paulo: Santa Ifigenia. 2003.

BYERLY, Carol R.

Fever of war: the influenza epidemic in the U.S. Army during World War I. New York: New York Univ. Press. 2005.

CORTÉS, José David.

Curas y políticos: mentalidad religiosa e

intransigencia en la diócesis de Tunja. Bogotá: Ministerio de Cultura. 1998.
CROSBY, Alfred.

America's forgotten pandemic. 2. ed. Cambridge: Cambridge University Press. 2003

DURÁN SÁNCHEZ, María Fernanda.

La gripe española en Bogotá: la epidemia de 1918. Bogotá: Alcaldía Mayor. 2006.

ECHEVERRI DÁVILLA, Beatriz.

La gripe española: la pandemia de 1918-1919.

Madrid: Centro de Investigaciones Sociológicas; Siglo XXI de España Editores. 1993.

EL BOYACENSE.

Tunja, serie 5, n.110, 7 abr. 1888; n. 700, 4 nov. 1918; n. 702, 9 nov. 1918; n. 709, 11 dic. 1918.

EL DEBER.

Tunja, n. 6, 27 sep. 1918; n.11, 1 nov. 1918; n. 12, 8 nov. 1918.

GARCÍA MEDINA, Pablo.

La epidemia de gripa. Revista Médica de Bogotá, Bogotá, n.436-437. dic. 1918.

GARCÍA USTA, Jorge.

El pensamiento médico: selección de textos médicos. Cartagena: Fondo Editorial del Bolívar Grande. 2000.

GOBERNACIÓN DE BOYACÁ.

Gobernación de Boyacá, Tunja. Libro de informes del gobernador de Boyacá a la Asamblea Departamental. 1919.

GUERRERO, Javier.

Los años del olvido. Bogotá: Editorial Tercer Mundo. 1991.

HOSPITAL...

Hospital de Caridad de Tunja. Libro de 
entradas y salidas. (Biblioteca ESE, Hospital San Rafael). 1915-1922.

IDEAM.

Instituto de Hidrología Meteorología y Estudios Ambientales. El medio ambiente en Colombia. Colombia. $2^{\text {a }}$ versión de la edición de 1998. Disponible en: http://www.ideam.gov.co/ publica/index4.htm. Acceso en :15 mar. 2008. 4 jun. 2001.

\section{JUNTA DE SOCORROS...}

Junta de Socorros de Bogotá. Epidemia de gripa, octubre y noviembre de 1918: exposición de la Junta de Socorros. 1918.

\section{LA LINTERNA.}

La Linterna, Tunja, n.438, 23 oct. 1918; n.439, 1 nov. 1918; n.441, 15 nov. 1918; n.444, 22 nov. 1918.

LAVERDE, Jorge.

Contribución al estudio de la epidemia de gripa en Bogotá, en 1918. Tesis (Grado) - Universidad Nacional de Colombia, Bogotá. 1918.

LLANO RESTREPO, María Clara; CAMPUZANO CIFUENTES, Marcela. La chicha, una bebida fermentada a través de la historia. Bogotá: Cerec/Instituto Colombiano de Antropología. 1994.

LONDOÑO VEGA, Patricia; LONDOÑO VÉLEZ, Santiago.

Vida diaria en las ciudades colombianas. In: Mejía Alvaro, Tirado (Ed.). Nueva historia de Colombia. t.4. Bogotá: Editorial Planeta. p.313-399. 1989.

MACHADO, Absalón.

Políticas agrarias en Colombia 1900-1960. Bogotá: Centro de Investigaciones para el Desarrollo; Editorial Universidad Nacional de Colombia. 1986.

MARTÍNEZ MARTÍN, Abel Fernando. El lazareto de Boyacá: lepra, medicina, iglesia y estado. Tunja: UPCT (Colección Investigación U.P.T.C, 3). 2006.

MARTÍNEZ MARTÍN, Abel Fernando; ALVARADO, Solney; CARVAJAL, Juan Fernando.

Aproximación histórica a la medicina y la salud pública en Tunja en el siglo XIX. Tunja: UPTC. 2002.

MARTÍNEZ MARTÍN, Abel Fernando; MANRIQUE ABRIL, Fred G.; MELÉNDEZ ALVAREZ, Bernardo F.

La pandemia de gripa de 1918 en Bogotá, Dynamis, Granada, v.27, p.287-307. 2007.

MARTíNEZ PONS, Manuel.

València al limit: la ciutat davant l'epidèmia de grip de 1918. Simat de la Valldigna: Edicions La Xara. 1999.

MIRANDA CANAL, Néstor.

La medicina colombiana de la regeneración a los años de la Segunda Guerra Mundial. In: Mejía Alvaro, tirado (Ed.). Nueva historia de Colombia. t.4. Bogotá: Editorial Planeta. p.257-284. 1989.

NOGUERA, Carlos Ernesto.

Medicina y política: discurso médico y prácticas higiénicas durante la primera mitad del siglo XX en Colombia. Medellín: Eafit. 2004.

ORTIZ MESA, Luís Javier.

Fusiles y plegarias: guerra de guerrillas en Cundinamarca, Boyacá y Santander,

1876-1877. Medellín: Universidad Nacional de Colombia; IME. 2004.

PALACIOS, Marco.

Entre la legitimidad y la violencia: Colombia 1875-1994. Bogotá: Grupo Editorial Norma. 1999.

PEÑUELA RODRÍGUEZ, Víctor.

Apuntaciones de geografía e historia médicas del departamento de Boyacá en la República de Colombia. Revista Médica de Bogotá, Bogotá, n.487-98, p.64-141. ene.-dic. 1923.

PHILLIPS, Howard; KILLINGRAY, David. (Ed.). The Spanish influenza pandemic of 1918-19: new perspectives. London: Routledge. 2003.

PORRAS GALLO, María Isabel.

Una ciudad en crisis: la epidemia de gripe de 1918-1919 en Madrid. Madrid: Facultad de Medicina Universidad Complutense. 1994.

QUEVEDO VÉLEZ, Emilio et al. Café y gusanos, mosquitos y petróleo: el tránsito desde la higiene hacia la medicina tropical y la salud pública en Colombia, 1873-1953. Bogotá: Universidad Nacional de Colombia. 2004.

REPORTE...

Reporte de los delegados de las Juntas Departamentales de Higiene. Revista de Higiene, Bogotá, año 9, n.115. ago. 1919.

\section{REVISTA DE HIGIENE.}

Revista de Higiene. Órgano de la Junta Central de Higiene de Colombia. Bogotá, n.103-105, 111, 115. 1917-1919.

ROJAS, Ulises.

El Hospital de Tunja. In: Correa, Ramón. Historia de Tunja. t.3. Tunja: Academia Boyacense de Historia. P.218-220. 1948.

USA.

Centers for Disease Control. Disponible en: http://www.cdc.gov/flu/pandemic/ 
Impacto de la pandemia de gripa de 1918-1919...

qanda_es.htm\#proxima. Acceso en:

26 jan. 2006. 2006

VAN HARTESVELDT, Fred. R. (Ed.).

The 1918-1919 pandemic of influenza: the urban impact in the Western world. Lewinston: E.

Mellen Press. 1992.
VEGA CANTOR, Renán.

Gente muy rebelde. Bogotá: Pensamiento Critico. 2000.

ZAMBRANO, Fabio.

La gripa asesina de 1918: lecturas dominicales.

El Tiempo, Bogotá, p.8-9. dic. 1987.

$\rightarrow \rightarrow \rightarrow<<$ 